Discussion Papers of the

Max Planck Institute for

Research on Collective Goods

2018/5

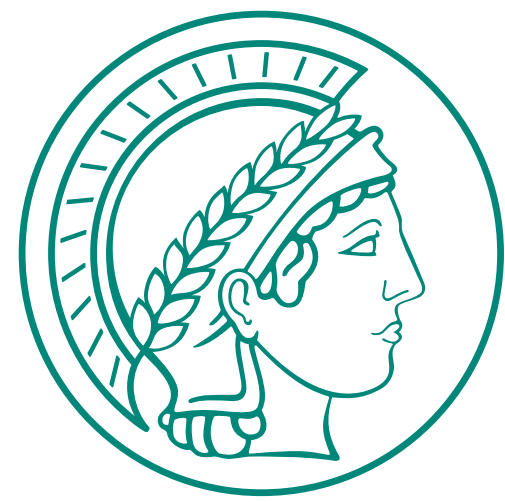

Debarment and Collusion in

Procurement Auctions

Claudia Cerrone

Yoan Hermstrüwer

Pedro Robalo 


\title{
Debarment and Collusion in Procurement Auctions
}

\author{
Claudia Cerrone / Yoan Hermstrüwer / Pedro Robalo
}

April 2018

Revised version: April 2021 


\title{
Debarment and Collusion in Procurement Auctions
}

\author{
Claudia Cerrone* $\quad$ Yoan Hermstrüwer $^{\dagger} \quad$ Pedro Robalo $^{\ddagger}$
}

\begin{abstract}
This article presents the first experiment exploring the impact of debarments - the exclusion of colluding bidders - on collusion in procurement auctions. We find that debarments reduce collusion and bids relative to a market with no sanction. The deterrent effect of debarments increases in the length of the punishment. However, shorter debarments reduce efficiency and increase the bids of non-debarred bidders. This suggests that debarments that are too lenient may trigger tacit collusion among the bidders who remain in the market, thereby facilitating the very behavior they aim to deter.
\end{abstract}

JEL codes: C92, D03, D44, K21, K42.

Keywords: debarment, collusion, procurement auctions, sanctions.

\section{Introduction}

Collusion is a pervasive phenomenon in public procurement auctions. The public provision of infrastructure, education and pharmaceuticals is particularly vulnerable to the concomitant harms of collusion, i.e. reduced competition and an increase in the cost of public projects. In order to prevent a wasteful use of taxpayer money, governments and international organizations devote substantial resources to the fight against collusion using different remedies (see e.g., U.S. Department of the Interior 2017; World Bank 2020; Kawai and Nakabayashi 2018).

One of the most important remedies used in response to anti-competitive practices, such as collusion, and other types of illegal behavior in procurement auctions is debarment. Debarment denotes the exclusion of bidders who have engaged in collusion or other illegal practices from future procurement auctions for a specified period of time. Enacted as administrative remedies by the US Congress in 1884 to prevent the government from working with bidders who are not "presently responsible" (U.S. Department of the Interior 2020), debarments were later used by governments and international development banks, such as the World Bank, as sanctions with a clear deterrence purpose. To date, the World Bank has debarred or otherwise 
sanctioned more than 900 companies and individuals, with debarments accounting for $93 \%$ of all sanctions (Dubois, Irving, and Smith 2019; World Bank 2017; Fariello and Bo 2015) and a considerable number of debarments being imposed to sanction collusion (World Bank 2019). In 2016, for instance, the World Bank debarred Schneider Electric Pakistan Pvt. Ltd, a switchgear manufacturer, for 25 months for orchestrating the winning bids in procurement auctions run under the Pakistan Electricity Distribution and Transmission Improvement Project. In 2019, the World Bank debarred Tiger IT Bangladesh Ltd for coordinating the technical specifications of the contract and orchestrating the procurement authorities' responses to other prospective bidders, all to their competitive advantage.

Despite their widespread use, evidence on the effects of debarments on anti-competitive bidding practices or other types of illegal behavior remains scarce. The only existing study on debarments is theoretical and focuses on their effect on corruption (Auriol and Søreide 2017). The study shows that debarments will effectively deter corruption in small markets if the probability of debarment is sufficiently high and if bidders sufficiently value contract awards in future procurement auctions - a finding that is consistent with the classical model of crime, according to which the deterrent effect of a sanction depends on its expected costs (Becker 1968). However, there is no empirical evidence on the effect of debarments on collusion in procurement auctions (e.g. price fixing, bid rigging, or bid rotation), the main reason being that collusive arrangements are usually surreptitious and therefore difficult to detect in practice (see e.g., Porter 2005; Kaplow 2011). In light of these epistemic constraints, experiments, as the one presented in this article, are particularly useful.

The answer to whether debarments effectively deter collusion is far from obvious. On the one hand, debarments are used as a sanction and should discourage collusive behavior. On the other hand, by reducing the size of procurement markets, debarments may facilitate collusion and higher bids among non-debarred bidders (Tirole 1988; Levenstein and Suslow 2006; Fonseca and Normann 2012). This problem may arise with respect to explicit collusion, i.e. any agreement aimed at limiting competition and sharing the surplus from non-competitive bidding (Marshall and Marx 2012), and to tacit collusion, i.e. the coordination of bids without explicit communication, side-contracting or transfers (see Ayres 1987; Cramton and Schwartz 2002; Bajari and Yeo 2009; Fonseca and Normann 2012). ${ }^{1}$ Irrespective of the specific mode of collusion, debarments may be a double-edged sword, as they may trigger the very behavior they are intended to deter.

This article reports evidence from the first experimental study on the impact of debarments on collusion and bidding behavior in procurement auctions. We explore whether debarment deters collusion by comparing it with the benchmark case of no sanction in a closed market, i.e. in a market without new entries. To explore how the deterrent effect of debarment varies with its length, we vary the length of bidder exclusion. Moreover, we explore whether and

1. Throughout this article, the terms explicit collusion and bidding rings are used interchangeably. 
how the exclusion of colluding bidders affects the bids of non-debarred bidders. Finally, we compare debarments with fines - the most common alternative to debarments in the practice of public authorities - to generate evidence on the conditions under which public authorities may apply both sanctions as equally effective substitutes. ${ }^{2}$

We find that the threat of debarment significantly reduces the frequency of collusion relative to the no sanction baseline, and decreases bids towards the competitive level. This deterrent effect increases with the length of the debarment. However, under the short debarment regime, the exclusion of colluding bidders increases the bids of non-debarred bidders. This suggests that the reduced thickness of the auction market generated by the exclusion of colluding bidders may facilitate tacit collusion among bidders who remain in the market. Interestingly, we do not observe this effect under the long debarment. The reason may be the following. The short debarment is less deterrent than the long one, which implies that debarments are more frequent. As a result, under the short debarment regime, non-debarred bidders interact in a smaller market for longer and thus have more time to learn about the additional earning opportunities offered by the reduced market size. Moreover, short debarments reduce efficiency, because bidder exclusions are more frequent and the bidder with the lowest cost is less likely to win the auction. Finally, we do not find a significant difference between the short debarment and the fine but for one result: the fine yields significantly higher efficiency levels than the short debarment.

To the best of our knowledge, we present the first experimental study on the impact of debarments on collusion in procurement auctions. On the one hand, we extend the small literature on debarment and corruption (Auriol and Søreide 2017) by exploring the effect of debarment on collusion. While Coey, Larsen, and Sweeney (2019) investigate the expected revenue drops resulting from a counterfactual bidder exclusion (i.e. a setup where the bidder exclusion is not observed in the data), we use a lab experiment to impose actual bidder exclusions as a sanction against collusion and quantify its effects. On the other hand, we contribute to the literature on collusion (Kaplow 2011; Engel 2015) and, more specifically, to the literature strand on collusion in procurement auctions (Milgrom and Weber 1982; Porter and Zona 1993, 1999; Pesendorfer 2000; Bajari and Ye 2003; Skrzypacz and Hopenhayn 2004; Fugger, Katok, and Wambach 2015; Brosig-Koch, Güth, and Weiland 2016).

Most experimental studies have focused on the impact of the auction format on bid rigging. $\mathrm{Hu}$, Offerman, and Onderstal (2011), for example, show that collusion rates are lower in the Amsterdam second-price auction than in the English auction and the first-price sealed-bid auction. Hinloopen and Onderstal (2014) find that antitrust policies tend to facilitate a breakdown of collusion in the first-price auction, while being largely ineffective in the English auction.

2. The World Bank has imposed fines in the Siemens case, in which the Siemens Group agreed to pay USD 100 million as part of a settlement agreement, but it is not clear whether the Bank has the legal authority to levy fines outside the framework of settlement agreements (Fariello and Bo 2015). Fines have also been levied to sanction collusion in procurement auctions for the supply of school milk in the US (Porter and Zona 1999). 
Recent experimental evidence suggests that this may be driven by the increased stability of collusion in the English auction relative to the first-price auction (Hinloopen, Onderstal, and Treuren 2020). In the setup explored by Llorente-Saguer and Zultan (2017), one bidder can bribe the other bidder to stay out of a first-price or second-price private-values auction, but the authors find no difference in bribing behavior across auction formats. Agranov and Yariv (2018) show that pre-play communication and post-auction side-payments in one-shot firstprice and second-price sealed-bid auctions entail a strong reduction of revenues, whereas the auction format has no effect on collusion. Finally, Noussair and Seres (2020) explore a secondprice sealed-bid auction with private and common value components, and find that collusion reduces efficiency.

Only a few experimental studies have narrowed down their focus on sanctions and, more specifically, fines (see Bigoni et al. 2012, 2015). Hamaguchi et al. (2007), for example, investigate the effect of fines in a repeated procurement auction. Hinloopen and Onderstal (2014) find that leniency programs yield stabler cartels and lower average winning cartel bids in first-price sealed-bid auctions than in English auctions. However, none of these studies has explored alternative remedies intended to weed out the vulnerability to collusion.

The remainder of our article is organized as follows. Section 2 discusses the legal background. Section 3 presents the theoretical model. We then present our experimental design and testable predictions in Section 4. Section 5 reports the results of the experiment. Section 6 concludes.

\section{Legal background}

Our study relates to a long-standing legal debate about the purpose and effects of debarments. Some authors have praised the deterrent effects of debarments and advocated their use as criminal sanctions against large corporations (Stevenson and Wagoner 2011). Others have categorized debarments as administrative tools (Tillipman 2012, 2013). Through the lens of administrative law, debarments are not part of criminal law and thus do not serve any punitive purpose, such as deterrence, retribution, or rehabilitation. Rather than disincentivizing a specific subset of potentially dishonest bidders (specific deterrence) or the entire set of potentially dishonest bidders (general deterrence), debarments are only intended to prevent presently dishonest bidders from contracting with the government with a view to relieving the strain on public budgets. Under administrative law, even if debarments were proven to deter future anti-competitive misconduct, such an effect would be considered as a mere coincidence and not as an intended effect.

In accordance with this non-punitive conceptualization of the purposes of debarments, the US Congress enacted the first debarment provision in the Act of July 5, 1884, which required the executive branch to award contracts to the "lowest responsible bidder" (U.S. Department of the Interior 2020). Stepping up this approach, the US legislator later established Subpart 
9.402(b) of the US Federal Acquisition Regulation providing that debarments are to be imposed "not for purposes of punishment" but "only in the public interest for the Government's protection". ${ }^{3}$ A similar administrative debarment regime is enshrined in Art. 57(4)(d) EU Procurement Directive 2014/24/EU. ${ }^{4}$ The upshot is that, by and large, debarments are not used as criminal sanctions but as administrative remedies aimed at protecting the government from imminent harm that irresponsible bidders may cause (Tillipman 2012, 2013).

The World Bank and other international development banks have taken a different approach to debarments. While debarments are formally qualified as administrative remedies (Dubois and Nowlan 2010; Dubois 2012; Leroy and Fariello 2012), they are explicitly designed to serve a similar purpose as criminal sanctions (Søreide, Groning, and Wandall 2016; Seiler and Madir 2012; Fariello and Daly 2013; Fariello and Bo 2015). Under Section 9.01 and Annex 1 of the World Bank Sanctions Procedures and the World Bank Sanctioning Guidelines, for example, all sanctions including debarments explicitly serve as a deterrent upon those who might otherwise engage in a misuse of Bank funds, especially through collusion - meaning arrangements between two or more parties designed to achieve an improper purpose, such as agreements between two or more bidders intended to establish bid prices at artificial, noncompetitive levels (Annex IV of the World Bank Procurement Regulations, Section 1.01 of the World Bank Sanctions Procedures).

\section{Theoretical framework}

In this section, we describe the theoretical framework. In Subsection 3.1, we present the benchmark game: a first-price sealed-bid procurement auction with the possibility to collude and no sanction. In Subsection 3.2, we introduce debarments as a sanction for collusive behavior.

\subsection{Benchmark auction game}

3. The US moved towards a more punitive regime with the Buy America Act (42 U.S.C. § 10), but there is no lack of plausible reasons why US lawmakers eventually refrained from making debarments part of the criminal sanctions toolkit. On the one hand, debarments as "administrative remedies" enable the administration to immediately respond to misconduct without having to rely on justice authorities and criminal courts to conduct a criminal procedure and impose "criminal sanctions". On the other hand, the standard of proof is lower in administrative law than in criminal law, which makes it easier to apply administrative remedies than criminal sanctions.

4. Accordingly, a contracting authority may exclude from a procurement procedure an economic operator if it "has sufficiently plausible indications to conclude that the economic operator has entered into agreements with other economic operators aimed at distorting competition". §§ 123, 124 of the German Antitrust Act (GWB) transpose the EU Procurement Directive 2014/24/EU, including provisions on statutory and discretionary debarments, into German law. 


\subsubsection{Model set-up}

The benchmark stage game has the following stages.

- Stage 0. Nature draws the private costs of two strong risk-neutral bidders and two weak risk-neutral bidders, denoted by $c_{i k}$, where $i \in\{1,2\}$ and $k \in\{s, w\} .^{5}$ Costs are private information.

- Stage 1. The strong bidders simultaneously decide whether or not to form a bidding ring. A bidding ring is formed if both strong bidders agree to collude. If no bidding ring is formed, the game proceeds to Stage 3. Weak bidders cannot join the bidding ring.

- Stage 2. If a bidding ring is formed, its members implement a first-price preauction knock-out, or PAKT (Mailath and Zemsky 1991; Kittsteiner 2003), to determine the designated bidder in the subsequent procurement auction and the side payment that the other strong bidder will receive.

- Stage 3. All the bidders participate in the procurement auction.

PAKT In the preauction knock-out, bidders bid for the right to be the designated bidder in the procurement auction. The bid is an offer to make a side payment to the other ring member. The ring member submitting the highest bid becomes the designated bidder in the procurement auction and makes a transfer to the other ring member. The other ring member submits a shill bid.

Procurement auction As in our experiment, each strong bidder's private cost $c_{i s}$ is independently drawn from a uniform distribution $U\left(c_{i s}\right)$ with support $\left[\underline{c}_{s}, \bar{c}_{S}\right]$, and each weak bidder's private $\operatorname{cost} c_{i w t}$ is independently drawn from a uniform distribution $U\left(c_{i w}\right)$ with support $\left[\underline{c}_{w}, \bar{c}_{w}\right]$, where $\underline{c}_{w}>\bar{c}_{s}$ and $\underline{c}_{S}>0 .{ }^{6}$ All bidders know their private costs and the distribution of the other bidders' private costs. Let $R$ denote the bid cap (the buyer's reserve price), where $R>\bar{c}_{w}$. We assume an efficient tie-breaking rule: if two or more bidders submit the same bid, the winning bidder is the one with the lowest cost. This implies that if the ring leader and a weak bidder submit the same bid, the ring leader will win the auction.

\subsubsection{Equilibrium analysis}

In what follows, we derive the perfect Bayesian Nash equilibrium. Following related literature, we assume that bidders of the same type use identical bidding strategies. The game is solved

5. We include weak bidders who are not allowed to form a bidding ring because we are interested in the effect of debarment on the behavior of non-debarred bidders. Moreover, in most auctions bidders have unequal bidding strength.

6. We opt for non-overlapping supports to keep the model tractable and the experimental design simple to understand. 
by backward induction. All the proofs for Section 3.1 can be found in Appendix B.1.

\section{Procurement auction}

Case I: No collusion in Stage 1 If the strong bidders choose not to form a bidding ring in Stage 1 of the game, Stage 3 is a competitive procurement auction. Each bidder $i$, of type $k$, simultaneously submits a sealed bid, $b\left(c_{i k}\right)$. The bidder submitting the lowest bid obtains the contract and receives $b\left(c_{i k}\right)-c_{i k}$, while the other bidders receive 0 . Each strong bidder $i$ maximizes the following expected payoff:

$$
\pi_{i s}^{N C}=\left(b\left(c_{i s}\right)-c_{i s}\right) \operatorname{Pr}\left(b\left(c_{i s}\right) \leq b\left(c_{j s}\right)\right)
$$

where $i \neq j{ }^{7}$ Strong bidders' symmetric equilibrium bidding function is:

$$
b\left(c_{i s}\right)=\frac{c_{i s}}{2}+\frac{\bar{c}_{s}}{2}
$$

Each weak bidder $i$ will set $b\left(c_{i w}\right)=c_{i w}$, as they cannot profitably win the auction anyway.

Case II: Collusion in Stage 1 If the strong bidders choose to collude in Stage 1 of the game, then one strong bidder will become the ring leader and the other strong bidder will submit a shill bid. In equilibrium the lowest-cost strong bidder, i.e. the strong bidder with the lowest cost, will be designated as the ring leader.

Assume that, for $i \in\{1,2\}$, weak bidder $i$ bids his private cost, $b\left(c_{i w}\right)=c_{i w}$ (Maskin and Riley 2000; Kaplan and Zamir 2012). The ring leader maximizes the following expected profit:

$$
\pi_{i s}^{C}=\left(b\left(c_{i s}\right)-c_{i s}\right) \operatorname{Pr}\left(b\left(c_{i s}\right) \leq b\left(\tilde{c}_{j w}\right)\right)
$$

where, for $j \neq i, \tilde{c}_{j w}$ denotes the weak bidders' lowest cost and thus $b\left(\tilde{c}_{j w}\right)$ denotes the minimum competing bid. The best response of the ring leader will depend on the costs supports and on his private cost.

$$
b\left(c_{i s}\right)= \begin{cases}b\left(c_{i s}\right)=\underline{c}_{w} & \text { if } c_{i s} \leq 2 \underline{c}_{w}-\bar{c}_{w} \\ b\left(c_{i s}\right)=\frac{c_{i s}}{2}+\frac{\bar{c}_{w v}}{2}>\underline{c}_{w} & \text { if } c_{i s}>2 \underline{c}_{w}-\bar{c}_{w}\end{cases}
$$

If $c_{i s} \leq 2 \underline{c}_{w}-\bar{c}_{w}$, the ring leader's equilibrium bid is the lower bound of the weak bidders' cost range and the ring leader will always win. This is what Maskin and Riley (2000) term the "Getty effect", after the art museum known for out-bidding its competitors. When a bidder is very strong (i.e. has a very low cost), his profit from winning will be so high that it pays him to be sure that he will outbid the weak bidders. If $c_{i s}>2 \underline{c}_{w}-\bar{c}_{w}$, the ring leader's equilibrium

7. Given that $\bar{c}<\underline{c}_{w}$ and $b\left(c_{i k}\right)$ is monotonically increasing in $c_{i k}$, the minimum competing bid will be the bid of the other strong bidder. 
bid is above the lower bound of the weak bidders' cost range. Weak bidders have a non-zero probability of winning - if $b\left(c_{i w}\right)<b\left(c_{i s}\right)$.

In our experiment, $\left[\underline{c}_{s}, \bar{c}_{s}\right]=[20,60]$ and $\left[\underline{c}_{w}, \bar{c}_{w}\right]=[80,120]$. Thus, if $c_{\text {is }} \leq 40, b_{i s}\left(c_{i s}\right)=$ $\underline{c}_{w}=80$, whereas if $c_{i s}>40, b_{i s}\left(c_{i s}\right)=\frac{c_{i s}}{2}+60>80$.

PAKT If a bidding ring is formed in Stage 1, the PAKT in Stage 2 takes place. The symmetric equilibrium bid in the PAKT, and thus the equilibrium side payment, is given by:

$$
\lambda\left(c_{i s}\right)= \begin{cases}\frac{1}{2}\left(\underline{c}_{w}-c_{i s}\right) & \text { if } c_{i s} \leq 2 \underline{c}_{w}-\bar{c}_{w} \\ \frac{1}{2}\left(\frac{\bar{c}_{w}}{2}-\frac{c_{i s}}{2}\right) & \text { if } c_{i s}>2 \underline{c}_{w}-\bar{c}_{w}\end{cases}
$$

The equilibrium side payment is part of the Bayesian equilibrium. The ring leader and the other ring member will earn the same in the PAKT. Thus, the ring member with the highest cost will not want to mimic the ring member with the lowest cost (see Appendix B.1).

Collusion decision A strong bidder will collude if the expected payoff from colluding, conditional on the other strong bidder joining the ring, is weakly higher than the expected payoff from not colluding. ${ }^{8}$ In the absence of any sanction, the expected payoff from colluding will exceed the expected payoff from not colluding for any private costs of the strong bidders. Thus, the strong bidders will always collude. Proposition 1 summarizes collusion and bidding behavior in the benchmark game with no sanction.

Proposition 1. In the absence of sanctions, the strong bidders will collude for any private cost. The equilibrium bid of the ring leader is:

$$
b\left(c_{i s}\right)= \begin{cases}b\left(c_{i s}\right)=\underline{c}_{w} & \text { if } c_{i s} \leq 2 \underline{c}_{w}-\bar{c}_{w} \\ b\left(c_{i s}\right)=\frac{c_{i s}}{2}+\frac{\bar{c}_{w}}{2}>\underline{c}_{w} & \text { if } c_{i s}>2 \underline{c}_{w}-\bar{c}_{w}\end{cases}
$$

\subsection{Auction game with debarment}

\subsubsection{Set-up}

As debarment implies the exclusion of colluding bidders for some periods, we must consider a dynamic auction game. Let $T$ denote the finite number of periods of the game. In the final period, $t=T$, the auction game with debarment is the same as the benchmark game, as no punishment can occur. In any period before the final one, $t<T$, if the strong bidders collude, they will be excluded from the auction for the following $\lambda$ periods with a probability of $p=$ 0.5. ${ }^{9}$ In any period $t<T$, if no bidder is debarred, the auction game includes the following stages.

8. We assume that, if indifferent, strong bidders collude.

9. In our experiment, we impose $T=16$ in all treatments, with $\lambda=0$ in the benchmark case, $\lambda=3$ in the short debarment treatment, and $\lambda=6$ in the long debarment treatment. 
- Stage 0. Nature draws the private costs of two strong risk-neutral bidders and two weak risk-neutral bidders, denoted by $c_{i k t}$, where $i \in\{1,2\}$ and $k \in\{s, w\}$. Costs are private information.

- Stage 1. The strong bidders simultaneously decide whether or not to form a bidding ring. A bidding ring is formed if both strong bidders agree to collude. If no bidding ring is formed, the game proceeds to Stage 3. Weak bidders cannot join the bidding ring.

- Stage 2. If a bidding ring is formed, its members implement a first-price preauction knock-out, or PAKT, to determine the designated bidder in the subsequent procurement auction and the side payment that the other strong bidder will receive.

- Stage 3. All the bidders participate in the procurement auction.

- Stage 4. If a bidding ring is formed and detected, its members are debarred from the auction for the next $\lambda$ periods.

When the strong bidders are debarred, only the costs of the weak bidders are drawn in Stage 0 and only weak bidders participate in the procurement auction in Stage 3. Stage 1, Stage 2 and Stage 4 do not take place.

\subsubsection{Equilibrium analysis}

The equilibrium bid in the procurement auction and in the PAKT remain the same as in the benchmark game. However, the decision to collude may change under debarment. The proofs for Section 3.2 can be found in Appendix B.2.

Collusion decision In the last period, the expected payoff from colluding under debarment is the same as that in the benchmark game with no sanction, as there is no future period where exclusion may occur. Strong bidders will collude for any private cost. In any period before the last, the expected profit from colluding is lower under debarment than under no sanction, as colluding bidders face a 50\% chance of not playing the game in the following period(s). Thus, the private cost threshold below which the strong bidders can sustain collusion in equilibrium is lower under debarment than under no sanction. That is, strong bidders will collude for a smaller range of private costs than under no sanction.

Proposition 2. Under debarment, in $t=T$ the strong bidders will collude for any private cost, as under no sanction. In any $t<T$, the private cost threshold below which the strong bidder will collude is lower than under no sanction.

It follows from Proposition 2 that, as the number of periods of debarment increases, the expected cost from being debarred increases and thus the private cost threshold below which 
the strong bidders will collude decreases. The longer the debarment, the smaller the range of private costs such that collusion can be sustained in equilibrium. ${ }^{10}$

Corollary 1. As the number of periods of debarment, $\lambda$, increases, the private cost threshold below which the strong bidder will collude decreases.

Weak bidders. Under debarment weak bidders know that, when the strong bidders are excluded, they are (alone) in a competitive auction and have a chance to win. Hence their equilibrium bid will be:

$$
b\left(c_{i w t}\right)=\frac{c_{i w t}}{2}+\frac{\bar{c}_{w}}{2}
$$

\section{Experimental design}

Our experiment proceeded in three parts (Figure 1). ${ }^{11}$ Part 1 and Part 2 were common to all treatments. Part 1 consisted of 8 rounds of a procurement auction with no opportunity to form bidding rings. Part 2 consisted of 8 rounds of a procurement auction with the opportunity to form bidding rings. Part 3 consisted of 16 rounds of a procurement auction with the opportunity to form bidding rings and our between-subjects sanctions treatment. Following related studies (see Hu, Offerman, and Onderstal 2011), we deliberately increased complexity over these three parts to facilitate subjects' understanding of the game. In particular, Part 1 and Part 2 were designed to let subjects experience respectively a competitive environment and a collusive environment before interacting in the more complex environment with both collusion and sanctions - i.e. our treatments - in Part 3.

Subjects were randomly assigned to groups of four at the beginning of the experiment. Each group consisted of two strong bidders and two weak bidders. Groups were fixed in each part, as debarment requires fixed groups. ${ }^{12}$ Because groups had to be fixed in the debarment treatment in Part 3, they also had to be in the other treatments and in the other parts. Moreover, fixed groups facilitate learning.

In Part 1 and Part 2, each subject was randomly assigned the role of strong or weak bidder at the beginning of each round. Reassigning the roles in each round ensured that subjects did not always play either in the role of weak bidder or in the role of strong bidder. The latter, in fact,

10. Using our experiment's parameters and setting $\delta=1$, we find that both our short debarment and our long debarment treatments should decrease collusion. It is reasonable to assume no discounting in the lab, as the time span of repetitions is extremely short.

11. At the beginning of the experiment, subjects knew they would participate in three parts but they received instructions for the next part only after the end of the previous part.

12. First, if we had debarred colluding bidders and then re-matched subjects into new groups, we would not have been able to observe the effect of debarment on the remaining bidders. Second, due to the exclusion of some strong bidders under debarment, re-matching subjects in each round would not have guaranteed that groups of weak and strong bidders would always be formed. 
would lead to (i) a very unequal income distribution in the experiment, (ii) different learning experiences for always-weak and always-strong bidders, and (iii) always-weak bidders feeling that they have been treated unfairly and thus playing resentfully.

At the beginning of Part 3, each subject was randomly re-matched with three subjects she had not previously interacted with (perfect strangers re-matching). ${ }^{13}$ Each subject was then assigned the role of strong or weak bidder, and kept this role for all 16 rounds of Part 3 . Thus, each group is one independent observation. As we had 48 subjects per treatment, this gives us 12 independent observations per treatment.

\begin{tabular}{|c|c|c|c|c|}
\hline No collusion & & Collusion & & Treatment \\
\hline $\begin{array}{l}8 \text { Periods } \\
4 \text { bidders }\end{array}$ & Fixed & $\begin{array}{l}8 \text { Periods } \\
4 \text { bidders }\end{array}$ & Perfect strangers & $\begin{array}{c}16 \text { Periods } \\
4 \text { bidders }\end{array}$ \\
\hline
\end{tabular}

Figure 1: Timeline of the experiment

\subsection{Basic game}

At the beginning of each round, each strong bidder was randomly assigned an individual cost from the distribution $U[20,60]$, whereas each weak bidder was randomly assigned an individual cost from $U[80,120]$. Costs were private information. ${ }^{14}$ The strong bidders then individually and simultaneously decided whether they wanted to form a bidding ring - neutrally referred to as an "agreement". ${ }^{15}$ The decision to form a bidding ring was made by clicking a button. No free-form communication was possible to bargain over the conditions of the agreement prior to the decision. A bidding ring was only formed if both the strong bidders decided to enter an agreement. Only the strong bidders learned whether a bidding ring had been formed.

If a bidding ring was not formed, all bidders proceeded to the procurement auction and placed their bids. If a bidding ring was formed, each strong bidder proceeded to a PAKT and simultaneously stated the side payment they would transfer to the other strong bidder if they became the designated bidder. The strong bidder stating the higher amount became the designated bidder. Side payments were enforced. While side payments cannot be enforced in so-called weak bidding rings, such as those involving bid rotation schemes, we deliberately opted for enforceable side payments - i.e. strong bidding rings - in order to avoid poten-

13. We did not additionally re-match subjects at the beginning of Part 2 in order to (i) avoid dependence between parts and (ii) keep the game as simple as possible for subjects. An additional re-matching would have overwhelmed subjects and distracted their attention from the task at hand.

14. In Part 3, we elicited the bidders' beliefs about the other bidders' costs, regardless of whether a ring was formed.

15. As mentioned above, strong bidders did not have this opportunity in Part 1. 
tial confounds, like trust and cheating (for evidence on strong bidding rings, see McAfee and McMillan 1992; Asker 2010). After the PAKT, the weak bidders and the designated bidder proceeded to the procurement auction. For the sake of simplicity, the designated bidder submitted both her own bid and a shill bid for the non-designated bidder.

In the procurement auction, all bidders could submit bids up to the bid cap $R=140$, this constraint being in place for weak bidders' own bids, strong bidders' own bids and shill bids. ${ }^{16}$ Tied bids were broken randomly. The bidder submitting the lowest bid won the auction and earned an amount equal to her bid. The other bidders did not earn anything. After the auction, each bidder learned whether she had won the auction and the others' bids. At the end of each round, we elicited bidders' beliefs about the other bidders' costs. The main purpose of the belief elicitation was to assess weak bidders' responses to debarment and their belief about potential bid inflation by the other weak bidder.

\subsection{Treatments}

The four treatments we implemented in Part 3 are summarized in Table 1. The baseline treatment without a sanction (No Sanction) consisted of 16 rounds of the basic game described in the previous section. In the treatments with the 6-period debarment (DebarLong) and the 3-period debarment (DebarShort), bidding rings were detected with a probability of $p=0.5$. While the probability of detection might depend on the severity of the sanction in practice, we assume an exogenous and constant probability of detection and only manipulate the severity of the sanction. In case of detection, both strong bidders were unable to bid in the auction for the 6 rounds or 3 rounds, respectively, following detection. Strong bidders could only be excluded together (never singly) and only for a ring formed in the current round (never for a ring formed in a previous round). Beliefs were always elicited, regardless of whether strong bidders were debarred, in order to prevent the risk of additional and undesired differences across treatments. Weak bidders participated in the auction as normal when strong bidders were debarred, and were informed about their debarment. ${ }^{17}$ This enables us to investigate whether debarment fosters tacit collusion among non-debarred bidders. Finally, we implemented a treatment with fines (Fine), where bidding rings were detected with a probability of $p=0.5$. In the event of detection, the fine was subtracted from the strong bidders' earnings up to that round (including the earnings in the current round). The amount of the fine was calibrated so as to be equivalent to the expected cost of being debarred for 3 rounds. As strong bidders forewent on average 8 points per round in the debarred rounds of DebarShort, the fine was set to 24 points.

16. Note that lowering the bid cap can be used as a means of reducing the incentives for collusion. An effective use of this tool, however, requires information about the distribution of costs that procurement authorities usually do not have. Our design accounts for this information problem and reflects the intuition that procurement authorities have an interest in attracting enough bidders and securing thick markets by adopting a bid cap that is sufficiently high.

17. Weak bidders, however, did not learn whether collusion had occurred. 
Table 1: Treatments

\begin{tabular}{lcc}
\hline Treatment & Severity & Probability \\
\hline No Sanction & & \\
DebarLong & 6 rounds & 0.5 \\
DebarShort & 3 rounds & 0.5 \\
Fine & 24 Points & 0.5 \\
\hline
\end{tabular}

As for any experimental design, some simplifications had to be made to keep the design easy for subjects to understand and allow for a tractable implementation. The key features of our design, however, closely mimic what happens in several procurement auctions carried out all over the world, especially those carried out by international development banks or used by public agencies and governments to award infrastructure contracts. For example, strong cartels like those in our experiment, where side payments are possible and defection within the cartel does not occur, are supported by both experimental (Phillips, Menkhaus, and Coatney 2003; Hamaguchi et al. 2007) and empirical evidence (Asker 2010). In addition to reporting detailed evidence of side payments, the latter study also provides evidence of bidding behavior in the internal preauction knock-out that the ring used to coordinate its activities, as well as evidence of weaker bidders (i.e. bidders whose stated reason for participating in the ring was receiving side payments). The presence of weak and strong bidders characterizes all those auctions in which some seriously interested bidders have the willingness and opportunity to collude, while the other bidders are merely hunting for a bargain $(\mathrm{Hu}$, Offerman, and Onderstal 2011). As to the specific implementation of collusion, our design is supported by empirical evidence showing that collusion in infrastructure procurement auctions takes the form of a serious bid combined with shill bids, rather than a bid rotation scheme (Porter and Zona 1993). With respect to treatments, our design captures the essential features of the sanctions process as carried out by several procurement authorities, especially international development banks. Accordingly, one of the most important parameters in the sanctions process is how severe a debarment should be or whether bidders should rather pay a fine, for example, as part of a settlement agreement (Fariello and Bo 2015; Dubois, Ezzeddin, and Swan 2016; Dubois, Irving, and Smith 2019).

\subsection{Procedure}

The experiment was programmed using the experimental software $z$-Tree (Fischbacher 2007) and conducted at the BonnEconLab of the University of Bonn in November 2017, with a total of 236 subjects. Subjects were recruited via hroot (Bock, Baetge, and Nicklisch 2014) and participated in 8 main sessions and 2 pilot sessions. The pilot sessions were used to calibrate the experiment. In this article, we only report the results from our 8 main sessions ( 2 sessions 
per treatment), with a total of 196 subjects (48 subjects per treatment). Before each part of the experiment, subjects had to answer control questions in order to proceed to the actual experiment. In each treatment, we measured risk preferences (Holt and Laury 2002), the impact of the number of competitors on competitiveness (Garcia and Tor 2009; Garcia, Tor, and Schiff 2013), ${ }^{18}$ and demographic characteristics. At the end of the experiment, subjects received the sum of their earnings in Part 1 and Part 2 or their earnings in Part 3, in addition to a show-up fee of 6 Euros. On average, subjects earned 17.04 Euros.

\subsection{Hypotheses}

In this subsection, we present our testable predictions, which follow from our theoretical analysis in Section 3. In Section 3 we show that, in the absence of sanctions, strong bidders will collude for any private costs.

\section{Hypothesis 1.}

Strong bidders are less likely to collude under debarments and fines than in the absence of any sanction.

\section{Hypothesis 2.}

Strong bidders are less likely to collude under the long debarment than under the short debarment.

Under sanctions, there will be fewer periods with non-competitive bidding. Therefore, strong bidders' bids will be lower under sanctions than without sanctions.

\section{Hypothesis 3.}

Strong bidders' bids are lower under debarments and fines than in the absence of any sanction.

As an additional check of the robustness of our experimental design, we ran a power analysis to determine the expected power of our tests, given a 5\% significance level, a certain size of our hypothesized effects, and 12 independent observations per treatment (Appendix C.5).

\section{Results}

\subsection{Summary}

Table 2 presents the collusion rates and the bids submitted by strong bidders in all parts of the experiment. In Part 3, collusion rates are higher in the no sanction baseline than under debarments and fines, and decrease with the length of the debarment (Figure 2). Similarly, bids are higher with no sanction than with debarments or fines, and decrease with the length of the debarment (Figure 3).

18. To control for ratio bias, we used the survey questions proposed by Denes-Raj and Epstein (1994). See Appendix C.4. 
Bids are markedly higher in Part 2, where collusion was possible, than in Part 1, where collusion was not possible. Moreover, as expected, we observe small differences in collusion levels across treatments in Part 2, and small differences in bids across treatments in Part 1 and Part 2. Part 3, however, features very strong variations of collusion levels and bids across treatments.

Table 2: Summary statistics for strong bidders

\begin{tabular}{lcccccc}
\hline & \multicolumn{2}{c}{ Part 1 } & \multicolumn{2}{c}{ Part 2 } & \multicolumn{2}{c}{ Part 3 } \\
Treatment & Collusion & Bids & Collusion & Bids & Collusion & Bids \\
\hline No Sanction & - & 49.69 & 0.85 & 74.64 & 0.92 & 81.87 \\
DebarLong & - & 47.10 & 0.81 & 72.12 & 0.23 & 49.09 \\
DebarShort & - & 48.98 & 0.87 & 72.82 & 0.58 & 59.98 \\
Fine & - & 46.68 & 0.92 & 79.01 & 0.48 & 58.47 \\
\hline$N$ & \multicolumn{3}{c}{768} & \multicolumn{3}{c}{768} \\
\hline
\end{tabular}

$N$ denotes the number of individual observations in each part. All reported values denote treatment averages, i.e. average collusion rates and average bids among strong bidders.

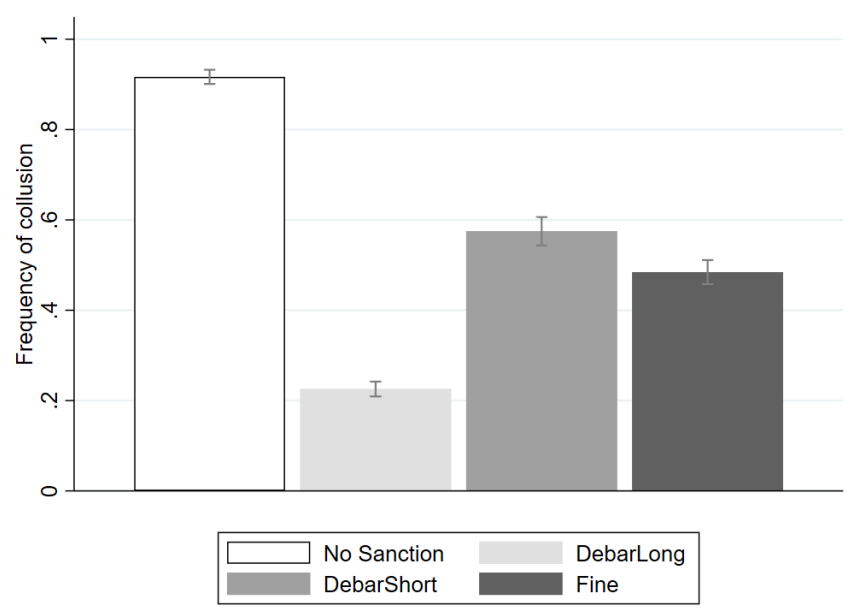

Figure 2: Mean frequency of collusion by treatment.

\subsection{Effect of debarment and fines}

\subsubsection{Collusion}

Following the literature (Hinloopen and Soetevent 2008; Bigoni et al. 2015; Chowdhury and Wandschneider 2018), collusion is a dummy variable taking value 1 when a strong bidder agrees to form a bidding ring, and 0 otherwise. To estimate our effects, we use Mann-Whitney tests at the group observation level. While collusion rates are as high as $91.7 \%$ in the no sanction baseline, they drop to to $22.6 \%$ in the long debarment treatment, to $57.5 \%$ in the short de- 


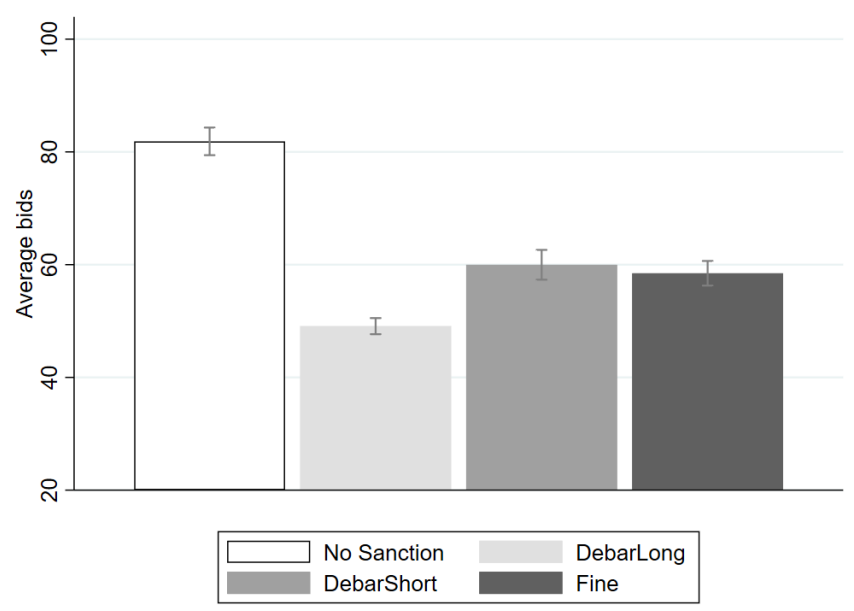

Figure 3: Mean strong bidders' bids by treatment.

barment treatment, and to $48.4 \%$ in the fines treatment. ${ }^{19}$ This drop in collusion rates generated by each of the three sanctions in comparison to the no sanction baseline is highly significant (Mann-Whitney, $p<0.01$ ).

In addition, we estimate OLS and logit regressions with the following basic specification:

$$
Y_{i g}=\beta_{0}+\beta_{1} \text { DebarLong }+\beta_{2} \text { DebarShort }+\beta_{3} \text { Fine }+\epsilon_{i g}
$$

where $\beta_{0}$ denotes the constant, and DebarLong, DebarShort and Fine are treatment dummies taking value 1 if $i$ participated in the treatment, and 0 otherwise. The indicator $i$ denotes each subject, the indicator $g$ the group to which subjects belong, and $\epsilon_{i g}$ the error term. To account for dependence arising from the repeated interaction within groups, standard errors are clustered at the level of groups consisting of two strong bidders and two weak bidders. We also estimate three-level mixed-effects logit models for collusion and three-level mixed-effects linear models for bids. This approach allows us to account for the dependence of each subject's and each group's observations over the 16 rounds in Part 3 (for a similar approach, see Hu, Offerman, and Onderstal 2011; Bigoni et al. 2012, 2015). ${ }^{20}$ Finally, we use Wald tests to assess differences across treatments and expect to reject the null when comparing the coefficients of our treatment dummies.

Table 3 presents the average marginal effects of the three sanctions on collusion relative to the no sanction baseline, as estimated in a logit model with standard errors clustered at the group level. In Column 1 we only control for the treatment dummies, in Column 2 we also control for private cost and risk aversion, and in Column 3 we also control for demographic

19. An alternative measure of collusion might consider the frequency of bidding rings rather than individual collusion propensities. Using this measure, the treatment effects become even larger. While bidding rings form in $83.3 \%$ of rounds in the no sanction baseline, they form in only $4.4 \%$ of rounds under the long debarment, in $40.6 \%$ of rounds under the short debarment, and in $26 \%$ of rounds under the fine.

20. A more detailed explanation of the model specifications and further results can be found in Appendix C.1. 
characteristics (age and gender). ${ }^{21}$ Confirming the results of the non-parametric tests, all our specifications show that the long debarment, the short debarment and the fine significantly reduce the frequency of collusion. This strongly supports Hypothesis 1.

Result 1. The frequency of collusion is significantly lower under debarments and under fines than in the absence of any sanction.

When comparing the long and the short debarment, we find that strong bidders were debarred much more frequently under the short debarment (in only $27.08 \%$ of all rounds) than under the long debarment (in $6.77 \%$ of all rounds). This difference can be explained by the fact that long debarment is more deterrent than short debarment, which supports Hypothesis 2.

Result 2. The frequency of collusion is significantly lower under the long debarment than under the short debarment.

When comparing the short debarment and the fine, we find no difference in the frequency of collusion (for a further comparison of the short debarment and the fine, see Subsection 5.3). Exploring the impact of risk preferences, we find that risk aversion explains a decrease in collusion. This indicates that more risk-averse subjects are more concerned about potential sanctions. Estimating a three-level random effects model (Table 10 in Appendix C), we obtain the same results.

Table 3: Impact of sanctions on collusion

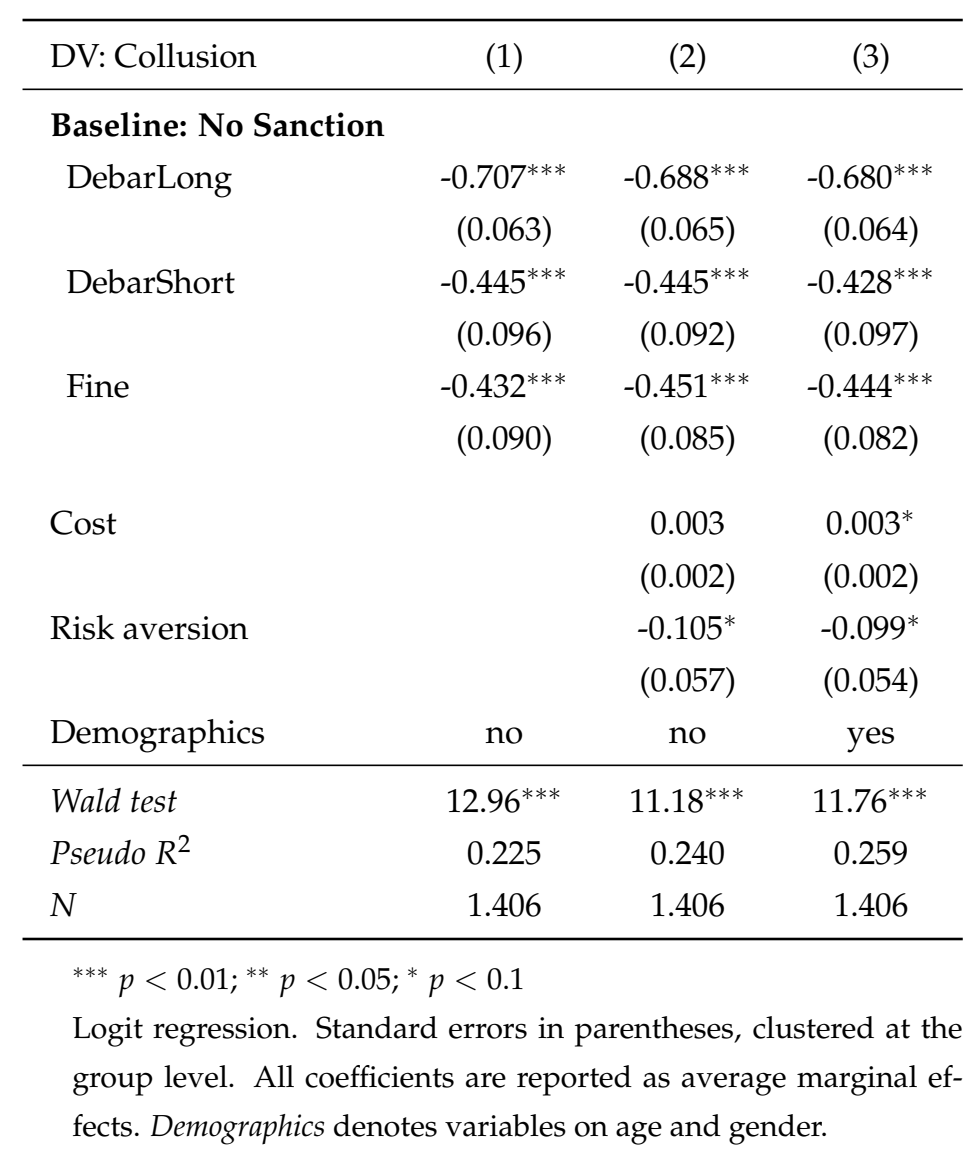

21. Controlling for round effects in order to account for experience does not change any of the results. 


\subsubsection{Bids}

Consistent with our results on the effect of the sanctions on collusion, we find that strong bidders' bids are significantly lower under debarments and fines than in the no sanction baseline (Mann-Whitney, $p<0.01) .{ }^{22}$ Table 4 presents the effect of the sanctions on strong bidders' bids using a linear regression model with standard errors clustered at the group level. Both debarments and fines significantly decrease strong bidders' bids, which supports Hypothesis 3. ${ }^{23}$ In addition, we find that the long debarment decreases strong bidders' bids more than the short debarment - an effect that corroborates our previous result. Estimating a three-level mixed-effects model (Table 11 in Appendix C.1), we obtain the same results.

Result 3. Strong bidders' bids are lower under debarments and under fines than in the absence of any sanction.

The price a procurement authority has to pay when implementing a first-priced procurement auction in practice is determined by the winning bid rather than the strong bidders' bid. To assess the robustness of our results, we therefore also analyze the effect of our sanctions on winning bids. While we observe the highest average winning bids under the no sanction baseline $(m=70.72)$, we observe a steep drop under the long debarment $(m=43.74)$ and the fine $(m=50.88$, Mann-Whitney, $p<0.001)$ relative to the no sanction baseline, but no decrease under the short debarment $(m=65.03$, Mann-Whitney, $p=0.200$ ) relative to the no sanction baseline. In line with this observation, our regression analysis shows that the long debarment and fines significantly reduce average winning bids, whereas the short debarment only yields a marginally significant decrease (Table 12 in Appendix C.1). This suggests that a short debarment may not effectively protect procurement authorities against non-competitive pricing and is unlikely to help reduce expenses associated with public contract awards.

Our analysis of the effect of sanctions both on strong bidders' and winning bids shows that the decrease in bids generated by the fine is stronger than that generated by the short debarment, which suggests a behavioral effect (for a detailed comparison, see Subsection 5.3). Apart from that, bidding behavior follows the patterns of standard theory. While higher costs lead to higher bids, risk aversion explains a decrease in bids. The latter is in line with our results on collusion. More risk-averse bidders submit lower bids, because they collude less and are thus more concerned about winning the auction in a competitive manner. Finally, we observe stable bidding patterns over all rounds across all treatments (see Table 5 in Appendix C.3). This suggests that none of the sanctions triggers any specific dynamics in the procurement auction game.

22. We only consider rounds in which colluding strong bidders are not debarred (non-debarred rounds), as including rounds in which strong bidders are excluded and cannot submit bids (debarred rounds), would artificially deflate bids.

23. While discouraging explicit collusion (i.e. the formation of bidding rings), sanctions could potentially induce strong bidders to tacitly collude. We find no evidence of such an effect. 
Table 4: Impact of sanctions on strong bidders' bids

\begin{tabular}{lccc}
\hline DV: Bids & $(1)$ & $(2)$ & $(3)$ \\
\hline Baseline: No Sanction & & & \\
DebarLong & $-32.442^{* * *}$ & $-31.188^{* * *}$ & $-30.496^{* * *}$ \\
& $(4.652)$ & $(4.689)$ & $(4.430)$ \\
DebarShort & $-17.439^{* * *}$ & $-17.442^{* * *}$ & $-16.676^{* * *}$ \\
& $(6.511)$ & $(6.301)$ & $(5.911)$ \\
Fine & $-23.401^{* * *}$ & $-23.853^{* * *}$ & $-23.258^{* * *}$ \\
& $(6.279)$ & $(6.228)$ & $(5.809)$ \\
Cost & & $0.617^{* * *}$ & $0.617^{* * *}$ \\
& & $(0.058)$ & $(0.058)$ \\
Risk aversion & & $-4.984^{*}$ & $-4.714^{*}$ \\
& & $(2.801)$ & $(2.600)$ \\
Demographics & no & no & yes \\
\hline Wald test & $13.34^{* * *}$ & $11.85^{* * *}$ & $11.91^{* * *}$ \\
$R^{2}$ & 0.253 & 0.353 & 0.382 \\
$N$ & 1.406 & 1.406 & 1.406 \\
\hline *** $p<0.01 ; * * p<0.05 ;{ }^{*} p<0.1$ & & \\
OLS. Standard errors in parentheses, clustered at the group level. De- \\
mographics denotes variables on age and gender. &
\end{tabular}

Figure 4 shows that some strong bidders submit bids above the weak bidders' lower cost bound, with supports Proposition 1. Moreover, while we do not find any evidence of underbidding, strong bidders tend to submit bids that are relatively close to their costs under the long debarment. This suggests that they do not try to tacitly collude by submitting higher bids.

\subsection{Comparison between debarment and fines}

In this subsection, as an extension, we compare the effect of the short debarment on collusion and strong bidders' bids with that of fines. The motivation underlying this comparison is that the legal competence to impose fines and debarments is often assigned to different public authorities (see e.g., Fariello and Bo 2015). As a result of the differing legal regimes, these sanctions may apply cumulatively in some cases, and exclusively in others. It is therefore of high practical relevance to assess the relative effectiveness of debarments and fines, especially with respect to cases where public authorities can coordinate their responses to collusion and may choose between fines and debarments. ${ }^{24}$ Our treatment with the fine is intended to pro-

24. Fines against cartels and the abuse of a dominant position are mainly enforced by the European Commission in the EU and by the Department of Justice in the US. Debarments, by contrast, are imposed by the respective suspension and debarment official in charge of the procurement procedure according to the conditions set out in one of the numerous debarment provisions. The relevant antitrust and debarment provisions can be found in the 


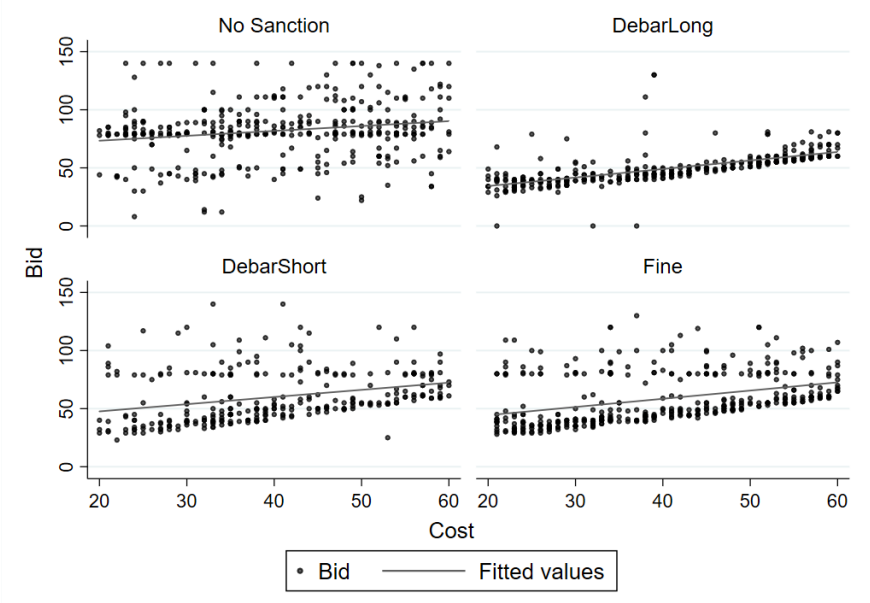

Figure 4: Strong bidders' bids as a function of the costs.

vide evidence on whether fines and debarments - holding their expected costs constant - may be used as substitutes, or whether they yield different deterrence levels due to behavioral effects. In the presence of loss aversion (see Kahneman and Tversky 1979), for example, the two sanctions could have a different effect on collusion and bids. While strong bidders may forego future and uncertain earnings in the debarment treatment, they may lose earnings they have already made in the fine treatment. If losing money already earned looms larger than foregoing potential future earnings, collusion should be less frequent in the fine treatment than in the debarment treatment.

In order to make the comparison as accurate as possible, we ran the short debarment treatment before the fine treatment, and used the average foregone earnings computed in the short debarment treatment to calibrate the severity of the fine. The expected cost of being fined ( 24 points) was equivalent to the expected cost of being debarred for three periods. ${ }^{25}$

We find some evidence in support of a behavioral effect. While strong bidders collude in $57.5 \%$ of rounds under the short debarment, they collude significantly less (in $48.4 \%$ of rounds) under the fine (Mann-Whitney, $p<0.01$ ). The decrease in collusion generated by the short debarment in comparison to the fine becomes even more pronounced when considering bidding rings rather than individual collusion propensities $(40.6 \%$ under the short debarment, $26 \%$ under the fine). This result, however, is not robust to a parametric analysis. Table 5 presents the effect of the short debarment on collusion (Column 1) and on bids (Column 2) relative to the fine. The decrease in collusion and bids generated by the short debarment is not significantly different from that generated by the fine. While this suggests that fines and debarments can be used as substitutes if expected costs are held constant, further evidence is

Introduction.

25. It is a standard approach for public authorities to impose legal sanctions based on an estimate of their expected costs (e.g. based on documentation about past expenses and the value of previous contract awards). The choice between fines and debarments will therefore usually be based on an approximation of the bidder's costs and benefits. 
needed.

Table 5: Effect of short debarment relative to fines

\begin{tabular}{|c|c|c|c|c|c|c|}
\hline & \multicolumn{3}{|c|}{ (1) } & \multicolumn{3}{|c|}{$(2)$} \\
\hline DV: & \multicolumn{3}{|c|}{ Collusion } & \multicolumn{3}{|c|}{ Bids } \\
\hline \multicolumn{7}{|l|}{ Baseline: Fine } \\
\hline \multirow[t]{2}{*}{ DebarShort } & -0.013 & 0.006 & 0.016 & 5.962 & 6.411 & 6.582 \\
\hline & $(0.115)$ & $(0.107)$ & $(0.107)$ & $(6.377)$ & $(5.910)$ & $(5.534)$ \\
\hline Cost & no & yes & yes & no & yes & yes \\
\hline Risk aversion & no & yes & yes & no & yes & yes \\
\hline Demographics & no & no & yes & no & no & yes \\
\hline (Pseudo) $R^{2}$ & 0.225 & 0.240 & 0.259 & 0.253 & 0.353 & 0.382 \\
\hline$N$ & 1.406 & 1.406 & 1.406 & 1.406 & 1.406 & 1.406 \\
\hline \multicolumn{7}{|c|}{${ }^{* * *} p<0.01$; $^{* *} p<0.05$; $^{*} p<0.1$} \\
\hline \multicolumn{7}{|c|}{ Column 1: Logit regression. Standard errors in parentheses, clustered at the group } \\
\hline \multicolumn{7}{|c|}{ level. Coefficients are reported as average marginal effects. Column 2: OLS. Standard } \\
\hline
\end{tabular}

\subsection{Weak bidders}

Our experiment was also designed to investigate the impact of the sanctions on weak bidders' bids. An observed increase of weak bidders' bids could be interpreted as evidence of tacit collusion, i.e. as the result of implied coordination on bids among weak bidders due to reduced competitive pressure from strong bidders. Given that competitive pressure is only reduced in rounds with a reduced number of bidders, we distinguish between rounds in which colluding strong bidders are excluded (debarred rounds) and rounds in which they were not (nondebarred rounds). When including debarred and non-debarred rounds, none of the sanctions has an effect on weak bidders' bids (Table 6, Column 1). When including debarred rounds only and estimating the effect of the short debarment relative to the long debarment, we observe marginally significantly higher bids under the short debarment $(m=106.34)$ than under the long debarment $(m=92.15)$ (Table 6, Column 2). ${ }^{26}$

Result 4 . Weak bidders' bids are higher under the short debarment than under the long debarment.

Our data suggest that this difference may be driven by the fact that the long debarment is more deterrent than the short debarment. As a consequence, debarment is more frequent in

26. Weak bidders' bids are even slightly higher under the short debarment than under no sanction $(m=103.16)$. In line with this observation, we find that the gap between weak bidders' bids and their belief on the other weak bidders' costs is higher under the short debarment than under no sanction, but equivalent under the long debarment and no sanction. 
the short debarment treatment than in the long debarment treatment. As a result, the strong bidders' probability of winning the auction is much lower under the short debarment (68.23\%) than in the other treatments (No Sanction: 86.46\%, DebarLong: 86.98\%, Fine: 92.71\%). More specifically, strong bidders are debarred in only $6.77 \%$ of all rounds in the long debarment treatment and in $27.08 \%$ of all rounds in the short debarment treatment. This implies that weak bidders are not exposed to strong bidders' competition for a much longer time in the short debarment treatment. Therefore, the short debarment gives weak bidders more opportunities to figure out how to make additional earnings. In other words, weak bidders' bids are higher under the short debarment because its deterrent effect on strong bidders is weaker than that of the long debarment.

Table 6: Impact of sanctions on weak bidders' bids

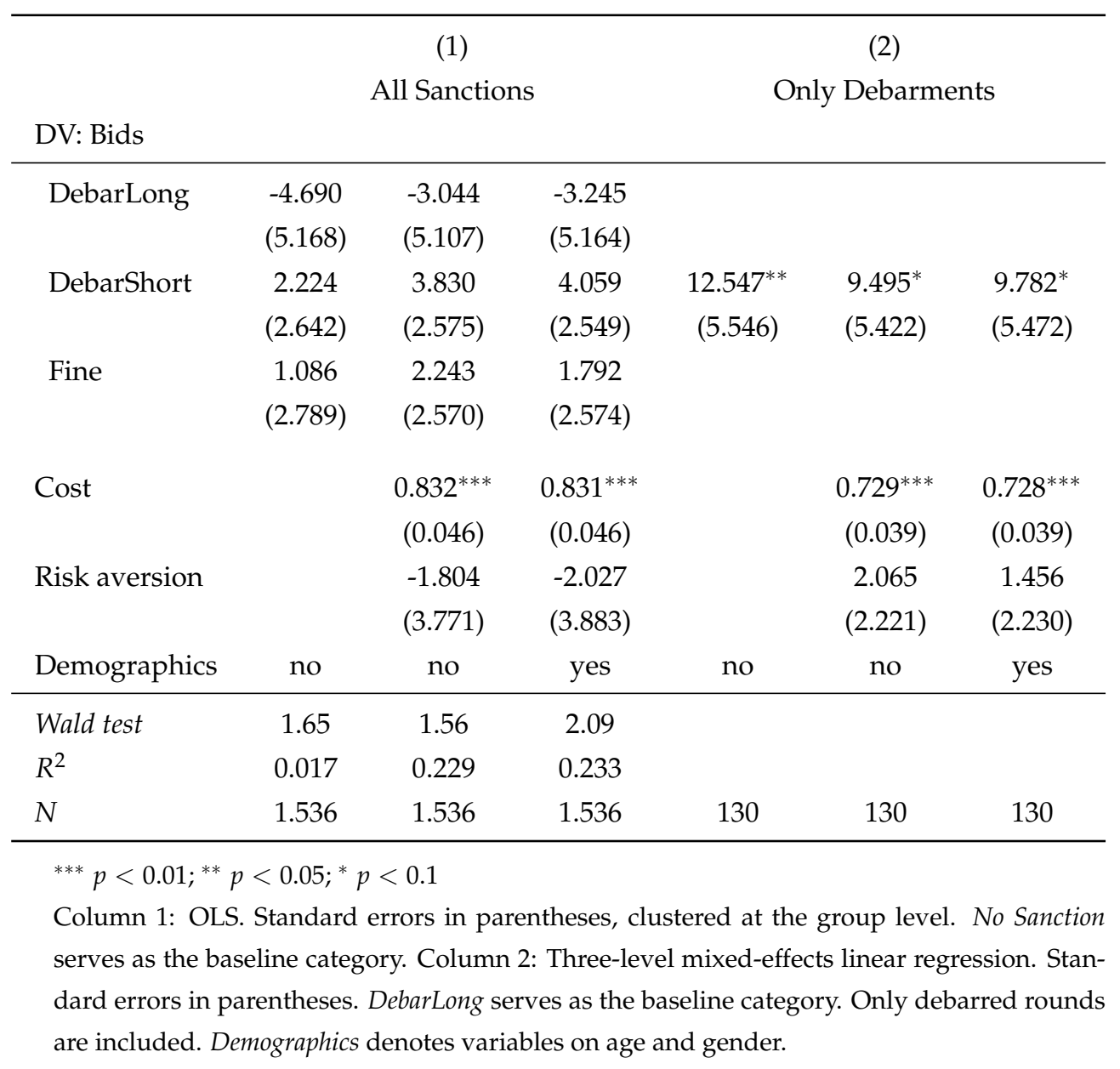

\subsection{Earnings}

Strong bidders. As strong bidders do not earn anything when being debarred, we only consider earnings in non-debarred rounds. Consistent with the effect of the sanctions on collusion and bids, earnings are lower in each of the sanctions regimes (DebarLong: $m=4.260$, DebarShort: $m=5.145$; Fine: $m=4.430$ ) than in the no sanction baseline ( $m=15.643$ ), the difference being highly significant (Mann-Whitney, $p<0.01$ ). Note that the fine has a stronger 
effect on the strong bidders' earnings than the short debarment and generates almost the same effect as the long debarment. Table 7 shows that all the sanctions significantly decrease earnings. This result is in line with the fact that strong bidders earned significantly more when a bidding ring was formed than when it was not formed (Mann-Whitney, $p<0.01$ ).

Table 7: Impact of sanctions on strong bidders' earnings

\begin{tabular}{lccc}
\hline DV: Earnings & $(1)$ & $(2)$ & $(3)$ \\
\hline Baseline: No Sanction & & & \\
DebarLong & $-11.262^{* * *}$ & $-10.837^{* * *}$ & $-10.711^{* * *}$ \\
& $(2.184)$ & $(2.278)$ & $(2.038)$ \\
DebarShort & $-6.425^{* *}$ & $-6.407^{* *}$ & $-6.080^{* *}$ \\
& $(2.819)$ & $(2.803)$ & $(2.609)$ \\
Fine & $-11.214^{* * *}$ & $-11.508^{* * *}$ & $-11.346^{* * *}$ \\
& $(2.248)$ & $(2.200)$ & $(1.985)$ \\
Cost & & $-0.336^{* * *}$ & $-0.335^{* * *}$ \\
& & $(0.029)$ & $(0.029)$ \\
Risk aversion & & -2.058 & -1.938 \\
& & $(1.431)$ & $(1.281)$ \\
Demographics & no & no & yes \\
\hline Wald test & $6.49^{* *}$ & $6.60^{* *}$ & $7.46^{* *}$ \\
$R^{2}$ & 0.140 & 0.233 & 0.255 \\
$N$ & 1.406 & 1.406 & 1.406 \\
\hline *** $p<0.01 ;{ }^{* *} p<0.05 ;{ }^{*} p<0.1$ & & \\
OLS. Standard errors in parentheses, clustered at the group level. De- \\
mographics denotes variables on age and gender. &
\end{tabular}

Weak bidders. Consistent with our results on bids and tacit collusion, we find no effect of the sanctions on weak bidders' earnings when including all rounds (Table 8, Column 1). However, when considering debarred rounds only and estimating the effect of the short debarment relative to the long debarment, we find that the short debarment yields a marginally significant increase of weak bidders' earnings relative to the long debarment (Table 8, Column 2).

Result 5. Weak bidders' earnings are higher under the short debarment than under the long debarment.

\subsection{Efficiency}

We define efficiency as the ratio $e=\frac{c_{\max }-c_{\text {winner }}}{c_{\max }-c_{\min }}$, i.e. as a continuous variable that takes value 1 when the lowest-cost strong bidder wins the auction, and lower values when other bidders win (for an equivalent measure, see Hu, Offerman, and Onderstal 2011). While the efficiency ratio is $71.9 \%$ under the short debarment, it is consistently higher in all other treatments (De- 
Table 8: Impact of sanctions on weak bidders' earnings

(1)

(2)

All Sanctions

Only Debarments

DV: Earnings

\begin{tabular}{lcccccc}
\hline DebarLong & -2.122 & -2.140 & -2.291 & & & \\
& $(3.312)$ & $(3.233)$ & $(3.248)$ & & & \\
DebarShort & 1.115 & 1.315 & 1.221 & $7.824^{* * *}$ & $9.495^{*}$ & $9.782^{*}$ \\
& $(1.509)$ & $(1.668)$ & $(1.418)$ & $(2.999)$ & $(5.422)$ & $(5.472)$ \\
Fine & -0.094 & 0.187 & -0.114 & & & \\
& $(1.561)$ & $(1.539)$ & $(1.471)$ & & & \\
Cost & & $-0.061^{*}$ & $-0.061^{*}$ & & $0.729^{* * *}$ & 0.728 \\
& & $(0.032)$ & $(0.032)$ & & $(0.039)$ & $(0.039)$ \\
Risk aversion & & -2.355 & -2.673 & & 2.065 & 1.456 \\
& & $(2.981)$ & $(3.031)$ & & $(2.221)$ & $(2.230)$ \\
Demographics & no & no & yes & no & no & yes \\
\hline Wald test & 1.34 & 1.29 & 2.60 & & & \\
$R^{2}$ & 0.009 & 0.022 & 0.035 & & & \\
$N$ & 1.536 & 1.536 & 1.536 & 130 & 130 & 130 \\
\hline
\end{tabular}

*** $p<0.01$; ${ }^{* *} p<0.05$; $^{*} p<0.1$

Column 1: OLS. Standard errors in parentheses, clustered at the group level. No Sanction serves as the baseline category. Column 2: Three-level mixed-effects linear regression. Standard errors in parentheses. DebarLong serves as the baseline category. Only debarred rounds are included. Demographics denotes variables on age and gender. 
barLong: $87.2 \%$, Fine: $92.3 \%$, No sanction: $87.7 \%$, Mann-Whitney, $p<0.001) .{ }^{27}$ Table 9 shows that the short debarment significantly reduces efficiency relative to the no sanction baseline, whereas the fine and the long debarment have no impact on efficiency. A further analysis reveals that the short debarment also reduces efficiency relative to the fine but not relative to the long debarment (Table 13 in Appendix C.2).

Result 6. The short debarment strongly decreases efficiency relative to no sanction and the fine.

Mirroring the results on the effects of our sanctions on winning bids, these efficiency losses imply that the short debarment comes at a high cost for procurement authorities. Accordingly, the average price paid is significantly higher under the short debarment $(m=65.03)$ than under the long debarment $(m=43.74)$ and under the fine $(m=50.88$, Mann-Whitney, $p<$ 0.01). In comparison to the no sanction baseline $(m=70.72)$, the short debarment entails no significant price drop (Mann-Whitney, $p=0.200$ ).

Table 9: Impact of sanctions on efficiency

\begin{tabular}{|c|c|c|c|}
\hline DV: Efficiency & (1) & (2) & (3) \\
\hline \multicolumn{4}{|c|}{ Baseline: No Sanction } \\
\hline \multirow[t]{2}{*}{ DebarLong } & -0.004 & -0.004 & -0.003 \\
\hline & $(0.087)$ & $(0.084)$ & $(0.085)$ \\
\hline \multirow[t]{2}{*}{ DebarShort } & $-0.158^{* *}$ & $-0.158^{* *}$ & $-0.159^{* *}$ \\
\hline & $(0.070)$ & $(0.069)$ & $(0.069)$ \\
\hline \multirow[t]{2}{*}{ Fine } & 0.047 & 0.047 & 0.048 \\
\hline & $(0.047)$ & $(0.047)$ & $(0.047)$ \\
\hline \multirow[t]{2}{*}{ Cost } & & $<0.001$ & $<0.001$ \\
\hline & & $(<0.001)$ & $(<0.001)$ \\
\hline \multirow[t]{2}{*}{ Risk aversion } & & 0.004 & 0.004 \\
\hline & & $(0.030)$ & $(0.030)$ \\
\hline Demographics & no & no & yes \\
\hline Wald test & $9.82^{* * *}$ & $9.89^{* * *}$ & $10.10^{* * *}$ \\
\hline$R^{2}$ & 0.060 & 0.060 & 0.060 \\
\hline$N$ & 3.072 & 3.072 & 3.072 \\
\hline
\end{tabular}

These results can be explained by the fact that the short debarment is less deterrent and thus more frequent than the long debarment. This decreases the probability of the lowest-cost strong bidder winning the auction, which drives down efficiency. Debarments of moderate length may hamper efficiency, as they increase the frequency of small markets with high-cost

27. These are conservative estimates. An alternative efficiency measure $e_{a}$ might consider separate efficiency ratios for non-debarred and debarred rounds $\left(e_{n}\right.$ and $\left.e_{d}\right)$ and the respective frequencies of these rounds $\left(f_{n}\right.$ and $\left.f_{d}\right): e_{a}=e_{n} \cdot f_{n}+e_{d} \cdot f_{d}$. Using this measure, the efficiency losses would be even larger. 
bidders only. If public authorities are concerned with efficiency, they should opt for either laissez faire or a sufficiently long and deterrent debarment regime.

\section{Conclusion}

Despite the widespread use of debarments to deter anti-competitive behavior in procurement auctions, the effect of debarments on collusion has not been put to any experimental or empirical test in the past. This article fills this gap and presents the results of the first experiment that explores the impact of debarments on collusion in procurement auctions. We compare debarments with a baseline of no sanction and investigate how the deterrent effect of debarments varies with their length.

First, we find that debarments strongly decrease collusion and bids, and that these effects increase with the length of the exclusion. Second, we observe that average winning bids are not lower under short debarments than in a non-competitive procurement auction. This prompts the conclusion that debarments may not effectively relieve strains on public budgets if they are not sufficiently deterrent, as procurement authorities are likely to end up paying the same amounts they would have to pay in a non-competitive procurement auction. A related downside of this result is that short debarments strongly reduce efficiency relative to the noncompetitive procurement auction and relative to fines, as the bidder with the lowest cost is less likely to win the auction. Third, fines and debarments - holding their expected costs equal and constant - do not differ in their effect on bidding rings and the bids of those able or willing to form a ring. However, fines yield higher efficiency and lower winning bids than debarments. Finally, we observe that short debarments increase the bids of non-debarred bidders. This suggests that debarments may trigger tacit collusion among the bidders who remain in the market. Interestingly, we do not observe this effect in the long debarment regime. One reason may be that the long debarment regime is much more deterrent than the short one. Weak bidders thus interact in a smaller market for a longer time in the short debarment regime than in the long one. As a result, in the short debarment regime they have more time to learn how to exploit the absence of strong bidders and of the competitive pressure they exert.

Our results have important implications for law and public policy. Public procurement authorities that rely on debarments to fight collusion may rest reassured: debarments can be used as an effective deterrent. However, our study provides evidence that debarments may have undesirable effects if applied with too much leniency. If debarments are not sufficiently deterrent, they will occur too often. As long as incumbent bidders do not face the threat of entry, this will likely facilitate tacit collusion among non-debarred bidders and reduce efficiency, as contracts will be awarded to bidders with higher costs.

Lawmakers and governments concerned with the threat of collusion and the efficient allocation of public funds may therefore want to opt for fines as the first-best solution. While fines - unlike debarments - do not mechanically reduce competition for a specified period, they 
usually also come along with monetary transfers to the buyer, which may benefit tax payers in the case of public procurement. Lawmakers and governments may, however, have to use debarments as a second-best solution in contexts where fines are not feasible, be it for political or legal reasons. Such regulatory constraints are likely to play a role when public procurement authorities lack the legal authority or tools to enforce fines, like in the context of procurement auctions run by international development banks. To prevent backfire effects and efficiency losses under these circumstances, lawmakers and governments should make sure to design and impose debarments that are sufficiently deterrent. Debarments that are too lenient may facilitate the very behavior they aim to curb.

\section{Acknowledgements}

We thank Phil Brookins, Christoph Engel, Vitali Gretschko, Oliver Kirchkamp, Nathan Maddix, Sander Onderstal, Gyula Seres, and conference participants at the 29th Annual Meeting of the American Law and Economics Association at Boston University (ALEA 2018), the 2nd Conference on Empirical Legal Studies in Europe at KU Leuven (CELSE 2018) and the 2019 INFORMS Annual Meeting in Seattle (INFORMS 2019) for helpful comments. Funding from the Max Planck Society is gratefully acknowledged.

Conflict of interest: none.

\section{References}

Agranov, Marina, and Leeat Yariv. 2018. "Collusion through communication in auctions." Games and Economic Behavior 107:93-108.

Asker, John. 2010. “A Study of the Internal Organization of a Bidding Cartel." American Economic Review 100 (3): 724-62.

Auriol, Emmanuelle, and Tina Søreide. 2017. "An economic analysis of debarment." International Review of Law and Economics 50:36-49.

Ayres, Ian. 1987. "How Cartels Punish: A Structural Theory of Self-Enforcing Collusion." Columbia Law Review 87 (2): 295-325.

Bajari, Patrick, and Lixin Ye. 2003. "Deciding Between Competition and Collusion." Review of Economics and Statistics 85 (4): 971-989.

Bajari, Patrick, and Jungwon Yeo. 2009. "Auction Design and Tacit Collusion in FCC Spectrum Auctions." Information Economics and Policy 21 (2): 90-100. 
Becker, Gary S. 1968. “Crime and Punishment: An Economic Approach.” Journal of Political Economy 76 (2): 169-217.

Bigoni, Maria, Sven-Olof Fridolfsson, Chloé Le Coq, and Giancarlo Spagnolo. 2012. “Fines, Leniency, and Rewards in antitrust." RAND Journal of Economics 43:368-390.

- 2015. "Trust, Leniency, and Deterrence." Journal of Law, Economics, and Organization 31:663-689.

Bock, Olaf, Ingmar Baetge, and Andreas Nicklisch. 2014. "hroot: Hamburg registration and organization online tool." European Economic Review 71:117-120.

Brosig-Koch, Jeannette, Werner Güth, and Torsten Weiland. 2016. "Comparing the effectiveness of collusion devices in first-price procurement: an auction experiment." Evolutionary and Institutional Economics Review 13 (2): 269-295.

Chowdhury, Subhasish M., and Frederick Wandschneider. 2018. "Antitrust and the 'Beckerian Proposition': the Effects of Investigation and Fines on Cartels." In Handbook of Behavioral Industrial Organization, edited by Victor Tremblay, Elizabeth Schroeder, and Carol Tremblay, 368-403. Edward Elgar Publishing Ltd.

Coey, Dominic, Bradley Larsen, and Kane Sweeney. 2019. “The bidder exclusion effect." RAND Journal of Economics 50 (1): 93-120.

Cramton, Peter, and Jesse A. Schwartz. 2002. "Collusive Bidding in the FCC Spectrum Auctions." Contributions in Economic Analysis \& Policy 1 (1): 1-18.

Denes-Raj, Veronika, and Seymour Epstein. 1994. "Conflict Between Intuitive and Rational Processing: When People Behave Against Their Better Judgment." Journal of Personality and Social Psychology 66 (5): 819-829.

Dubois, Pascale Hélène. 2012. “Domestic and International Administrative Tools to Combat Fraud \& Corruption: A Comparison of US Suspension and Debarment with the World Bank's Sanctions System." University of Chicago Legal Forum, 195-235.

Dubois, Pascale Hélène, Paul Ezzeddin, and Collin David Swan. 2016. "Suspension and Debarment on the International Stage: Experiences in the World Bank's Sanctions System." Public Procurement Law Review 25 (3): 61-70.

Dubois, Pascale Hélène, Giuliana Dunham Irving, and Jamieson Andrew Smith. 2019. Enforcer Overview: World Bank. In Americas Investigations Review 2020, 92-101. Global Investigations Review.

Dubois, Pascale Hélène, and Aileen Elizabeth Nowlan. 2010. “Global Administrative Law and the Legitimacy of Sanctions Regimes in International Law." Yale Journal of International Law $36: 15-25$. 
Engel, Christoph. 2015. “Tacit Collusion: The Neglected Experimental Evidence.” Journal of Empirical Legal Studies 12:535-577.

Fariello, Frank A., and Giovanni Bo. 2015. “Development-Oriented Alternatives to Debarment as an Anticorruption Accountability Tool." In The World Bank Legal Review Volume 6 Improving Delivery in Development: The Role of Voice, Social Contract, and Accountability, 415435.

Fariello, Frank A., and Conrad C. Daly. 2013. "Coordinating the Fight against Corruption among MDBs: The Past, Present, and Future of Sanctions." George Washington International Law Review 45:253-268.

Fischbacher, Urs. 2007. "z-Tree: Zurich toolbox for ready-made economic experiments." Experimental Economics 10:171-178.

Fonseca, Miguel A., and Hans-Theo Normann. 2012. "Explicit vs. tacit collusion: The impact of communication in oligopoly experiments." European Economic Review 56:1759-1772.

Fugger, Nicolas, Elena Katok, and Achim Wambach. 2015. “Collusion in Dynamic BuyerDetermined Reverse Auctions." Management Science 62 (2): 518-533.

Garcia, Stephen M., and Avishalom Tor. 2009. “The N-Effect.” Psychological Science 20:871-877.

Garcia, Stephen M., Avishalom Tor, and Tyrone M. Schiff. 2013. “The Psychology of Competition." Perspectives on Psychological Science 8:634-650.

Hamaguchi, Yasuyo, Toshiko Ishikawa, Masayuki Ishimoto, Yuji Kimura, and Tadanobu Tanno. 2007. An Experimental Study of Procurement Auctions with Leniency Programs. Technical report. Competition Policy Research Center Discussion Paper, Atomi University.

Hinloopen, Jeroen, and Sander Onderstal. 2014. "Going once, going twice, reported! Cartel activity and the effectiveness of antitrust policies in experimental auctions." European Economic Review 70:317-336.

Hinloopen, Jeroen, Sander Onderstal, and Leonard Treuren. 2020. "Cartel stability in experimental first-price sealed-bid and English auctions." International Journal of Industrial Organization 71:102642.

Hinloopen, Jeroen, and Adriaan R. Soetevent. 2008. "Laboratory evidence on the effectiveness of corporate leniency programs." RAND Journal of Economics 39 (2): 607-616.

Holt, Charles A., and Susan K. Laury. 2002. "Risk Aversion and Incentive Effects." American Economic Review 92:1644-1655.

$\mathrm{Hu}$, Audrey, Theo Offerman, and Sander Onderstal. 2011. "Fighting collusion in auctions: An experimental investigation." International Journal of Industrial Organization 29:84-96. 
Kahneman, Daniel, and Amos Tversky. 1979. "Prospect Theory: An Analysis of Decision under Risk." Econometrica 47 (2): 263-291.

Kaplan, Todd R., and Shmuel Zamir. 2012. "Asymmetric first-price auctions with uniform distributions: analytic solutions to the general case." Economic Theory 50:269-302.

Kaplow, Louis. 2011. "Direct versus Communications-Based Prohibitions on Price Fixing." Journal of Legal Analysis 3 (2): 449-538.

Kawai, Kei, and Jun Nakabayashi. 2018. "Detecting Large-Scale Collusion in Procurement Auctions." Working Paper.

Kittsteiner, Thomas. 2003. "Partnerships and double auctions with interdependent valuations." Games and Economic Behavior 44 (1): 54-76.

Leroy, Anne-Marie, and Frank Fariello. 2012. The World Bank Group Sanctions Process and Its Recent Reforms. World Bank Publications.

Levenstein, Margaret C., and Valerie Y. Suslow. 2006. “What Determines Cartel Success?” Journal of Economic Literature 44:43-95.

List, John A., Sally Sadoff, and Mathis Wagner. 2011. "So you want to run an experiment, now what? Some simple rules of thumb for optimal experimental design." Experimental Economics 14:439-457.

Llorente-Saguer, Aniol, and Ro'i Zultan. 2017. “Collusion and information revelation in auctions." European Economic Review 95:84-102.

Mailath, George J., and Peter Zemsky. 1991. "Collusion in second price auctions with heterogeneous bidders." Games and Economic Behavior 3 (4): 467-486.

Marshall, Robert C., and Leslie M. Marx. 2012. The Economics of Collusion: Cartels and Bidding Rings. MIT Press: Cambridge / London.

Maskin, Erik, and John Riley. 2000. “Asymmetric Auctions.” Review of Economic Studies 67:413438.

McAfee, R. Preston, and John McMillan. 1992. "Bidding Rings." American Economic Review 82:579-599.

Milgrom, Paul R., and Robert J. Weber. 1982. "A Theory of Auctions and Competitive Bidding." Econometrica 50 (5): 1089-1122.

Noussair, Charles N., and Gyula Seres. 2020. "The effect of collusion on efficiency in experimental auctions." Games E Economic Behavior 119:267-287.

Pesendorfer, Martin. 2000. "A Study of Collusion in First-Price Auctions." Review of Economic Studies 67 (3): 381-411. 
Phillips, Owen R., Dale J. Menkhaus, and Kalyn T. Coatney. 2003. “Collusive Practices in Repeated English Auctions: Experimental Evidence on Bidding Rings." American Economic Review 93 (3): 965-979.

Porter, Robert H. 2005. “Detecting Collusion.” Review of Industrial Organization 26:147-167.

Porter, Robert H., and J. Douglas Zona. 1993. "Detection of bid rigging in procurement auctions." Journal of Political Economy 101:518-538.

. 1999. "Ohio School Milk Markets: An Analysis of Bidding." RAND Journal of Economics 30:263-288.

Seiler, Norbert, and Jelena Madir. 2012. "Fight Against Corruption: Sanctions Regimes of Multilateral Development Banks." Journal of International Economic Law 15:5-28.

Skrzypacz, Andrzej, and Hugo Hopenhayn. 2004. "Tacit collusion in repeated auctions." Journal of Economic Theory 114 (1): 153-169.

Søreide, Tina, Linda Groning, and Rasmus Wandall. 2016. "An Efficient Anticorruption Sanctions Regime-The Case of the World Bank." Chicago Journal of International Law 16:523-552.

Stevenson, Drury D., and Nicholas J. Wagoner. 2011. "FCPA Sanctions: Too Big to Debar?" Fordham Law Review 80 (2): 775-820.

Tillipman, Jessica. 2012. "A House of Cards Falls: Why "Too Big to Debar" Is All Slogan and Little Substance." Fordham Law Review Res Gestae 80:49-58.

. 2013. "The Congressional War on Contractors." George Washington International Law Review 45:235-251.

Tirole, Jean. 1988. The Theory of Industrial Organization. MIT Press: Cambridge / London.

U.S. Department of the Interior. 2017. ISDC Report FY 2017. Technical report. Interagency Suspensions \& Debarment Comittee.

- 2020. A Brief History of the Debarment Remedy. Technical report. Interagency Suspensions \& Debarment Comittee. https: / / www.doi.gov / sites / doi.gov / files / migrated / pam / programs/acquisition/upload/Brief-History-of-Debarment-Remedy_Final-3_2_15.pdf.

World Bank. 2017. 10-Year Update on Case Data E Metrics: 2007-2017. Technical report. Office of Suspension and Debarment.

2019. Law Digest 2019. Technical report. World Bank Group Sanctions Board. 2020. Sanctions System - Annual report FY2020. Technical report. World Bank Group. 


\section{Appendices}

\section{A Auction game with fines}

In $t=T$, the auction game with fines is equivalent to the benchmark game. In any period $t<T$, the auction game with fines includes the following stages.

- Stage 0 to Stage 3. As in the benchmark game.

- Stage 4. If a bidding ring is formed, it will be detected with some probability $p=0.5$. When a bidding ring is detected, its members pay a fine $f$ in $t+1$.

In the last period, the expected payoff from colluding under fines is the same as that in the benchmark game, as there is no future period where punishment can occur. In each of the previous periods, the expected profit from collusion is lower under fines than under no sanction. Strong bidders will collude for any private cost. In any period before the last, the expected profit from collusion is lower than under no sanction, as colluding bidders face a $50 \%$ chance of being fined in the following period. The private cost threshold below which strong bidders can sustain collusion in equilibrium is lower than under no sanction. That is, strong bidders will collude for a smaller range of private costs than under no sanction.

Proposition 3. Under a fine, in $t=T$ the strong bidders will collude for any private cost, as under no sanction. In any $t<T$, the private cost threshold below which the strong bidders will collude is lower than under no sanction.

Proof. See Appendix B.3.

\section{B Proofs}

\section{B.1 Benchmark game}

\section{Proof of Proposition 1}

Case I: No collusion in Stage 1 For $i \in(1,2)$. strong bidder $i$ maximizes the expected profit:

$$
\begin{aligned}
\pi_{i s}^{N C} & =\left(b\left(c_{i s}\right)-c_{i s}\right) \operatorname{Pr}\left(b\left(c_{i s}\right) \leq b\left(c_{j s}\right)\right) \\
& =\left(b\left(c_{i s}\right)-c_{i s}\right)\left[1-F_{s}\left(c_{i s}\right)\right]
\end{aligned}
$$

where $i \neq j{ }^{28}$ Taking the first order condition and rearranging yields

28. Given that $\bar{c}_{s}<\underline{c}_{w}$ and $b\left(c_{i k}\right)$ is monotonically increasing in $c_{i k}$, the minimum competing bid will be the bid of the other strong bidder. 


$$
b^{\prime}\left(c_{i s}\right)\left[1-F_{s}\left(c_{i s}\right)\right]+\left(b\left(c_{i s}\right)-c_{i s}\right)\left(-f\left(c_{i s t}\right)\right)=0
$$

It follows that the symmetric equilibrium bidding function is:

$$
b\left(c_{i s}\right)=\frac{1}{\left[1-F_{s}\left(c_{i s}\right)\right]} \int_{c_{i s}}^{\bar{c}_{s}} t f(t) d t
$$

where $t$ is the integration constant. For $F_{s}\left(c_{i s}\right)=U\left[\underline{c}_{s}, \bar{c}_{s}\right]$,

$$
\begin{aligned}
& b\left(c_{i s}\right)=\frac{1}{1-\frac{c_{i s}-\mathcal{c}_{s}}{\overline{\bar{c}}_{s}-\underline{-}_{s}}} \int_{c_{i s}}^{\bar{c}_{s}} t f_{s}(t) d t \\
& =\frac{1}{\frac{\bar{c}_{s}-c_{i s}}{\overline{\bar{c}}_{s}-\underline{c}_{s}}} \frac{1}{\bar{c}_{s}-\underline{c}_{s}}\left[\frac{t^{2}}{2}\right]_{c_{i s}}^{\bar{c}_{s}} \\
& =\frac{c_{i s}}{2}+\frac{\bar{c}_{s}}{2}
\end{aligned}
$$

Case II: Collusion in Stage 1 Assume that, for $j \in(1,2), b\left(c_{j w}\right)=c_{j w}$. The ring leader's expected profit is:

$$
\pi_{i s}^{C}=\left(b\left(c_{i s}\right)-c_{i s}\right) \operatorname{Pr}\left(b\left(c_{i s}\right) \leq b\left(\tilde{c}_{j w}\right)\right)
$$

where, for $j \neq i, \tilde{c}_{j w}$ denotes the weak bidders' lowest cost and thus $b\left(\tilde{c}_{j w}\right)$ denotes the minimum competing bid. Setting $b\left(c_{i s}\right)=\underline{c}_{w}+\epsilon$,

$$
\pi_{i s}^{C}=\left(\underline{c}_{w}+\epsilon-c_{i s}\right)\left(1-F_{s}(\epsilon)\right)
$$

Taking the first order condition yields:

$$
\left(1-F_{s}(\epsilon)\right)-\left(\underline{c}_{w}+\epsilon-c_{i s}\right) f_{s}(\epsilon)=0 .
$$

For $\epsilon=0$,

$$
1-\left(\underline{c}_{w}-c_{i s}\right) f_{s}(0) \leq 0
$$

Rearranging,

$$
\begin{gathered}
1-\frac{\underline{c}_{w}-c_{i s}}{\bar{c}_{w}-\underline{c}_{w}} \leq 0 \\
\frac{c_{i s}}{\bar{c}_{w}-\underline{c}_{w}} \leq \frac{\underline{c}_{w}}{\bar{c}_{w}-\underline{c}_{w}}-1 \\
c_{i s} \leq 2 \underline{c}_{w}-\bar{c}_{w}
\end{gathered}
$$

Thus, if $c_{i s} \leq 2 \underline{c}_{w}-\bar{c}_{w}, \epsilon=0$ and the ring leader's best response is $b\left(c_{i s}\right)=\underline{c}_{w}$. For $\epsilon>0$, 


$$
1-\frac{\epsilon}{\bar{c}_{w}-\underline{c}_{w}}-\frac{\underline{c}_{w}+\epsilon-c_{i s}}{\bar{c}_{w}-\underline{c}_{w}}=0
$$

Rearranging,

$$
\begin{gathered}
\frac{2 \epsilon}{\bar{c}_{w}-\underline{c}_{w}}=1-\frac{\underline{c}_{w}-c_{i s}}{\bar{c}_{w}-\underline{c}_{w}} \\
2 \epsilon=\bar{c}_{w}-2 \underline{c}_{w}+c_{i s} \\
\epsilon=\frac{c_{i s}}{2}-\frac{\left(2 \underline{c}_{w}-\bar{c}_{w}\right)}{2}
\end{gathered}
$$

Thus, if $c_{i s}>2 \underline{c}_{w}-\bar{c}_{w}$, the ring leader's best response is:

$$
b\left(c_{i s}\right)=\underline{c}_{w}+\left[\frac{c_{i s}}{2}-\frac{\left(2 \underline{c}_{w}-\bar{c}_{w}\right)}{2}\right]=\frac{c_{i s}}{2}+\frac{\bar{c}_{w}}{2}>\underline{c}_{w}
$$

PAKT The ring leader and the other ring member will earn the same in the PAKT. If $c_{i s} \leq 2 \underline{c}_{w}-$ $\bar{c}_{w}$, the ring leader will earn

$$
\underline{c}_{w}-c_{i s}-\frac{1}{2}\left(\underline{c}_{w}-c_{i s}\right)=\frac{1}{2}\left(\underline{c}_{w}-c_{i s}\right),
$$

which agains equals the side payment to the other ring member. If $c_{i s}>2 \underline{c}_{w}-\bar{c}_{w}$, the ring leader will earn

$$
\frac{\bar{c}_{w}}{2}-\frac{c_{i s}}{2}-\frac{1}{2}\left(\frac{\bar{c}_{w}}{2}-\frac{c_{i s}}{2}\right)=\frac{1}{2}\left(\frac{\bar{c}_{w}}{2}-\frac{c_{i s}}{2}\right),
$$

which equals the side payment to the other ring member.

It follows that if the highest-cost strong bidder mimicked the lowest-cost strong bidder, she would earn less than if she did not mimic her.

Collusion decision Given the equilibrium bid in equation (1), a strong bidder's expected profit from not colluding is

$$
\pi_{i s}^{N C}=\frac{1}{2}\left(\bar{c}_{s}-c_{i s}\right) \operatorname{Pr}\left(b\left(c_{i s}\right) \leq b\left(c_{j s}\right)\right),
$$

where $b\left(c_{j s}\right)$ denotes the competing bid.

For the expected profit from colluding, two cases must be considered.

Case (i). Suppose that, for $i \in(1,2), c_{i s} \leq 2 \underline{c}_{w}-\bar{c}_{w}$. Given the equilibrium bid in equation (2) and the equilibrium side payment in (3), a strong bidder's expected profit from colluding is

$$
\pi_{i s}^{C}=\frac{1}{2}\left(\underline{c}_{w}-c_{i s}\right) \operatorname{Pr}\left(b\left(c_{i s}\right) \leq b\left(\tilde{c}_{j w}\right)\right)
$$


where $b\left(\tilde{c}_{j w}\right)$ denotes the minimum competing bid. As $\underline{c}_{w}>\bar{c}_{s}$ and $\operatorname{Pr}\left(b\left(c_{i s}\right)<b\left(c_{j s}\right)\right)<$ $\operatorname{Pr}\left(b\left(c_{i s}\right)<b\left(\tilde{c}_{j w}\right)\right)$, it follows that (A2) is higher than (A1) for any $c_{i s} \leq 2 \underline{c}_{w}-\bar{c}_{w}$.

Case (ii). Suppose that, for $i \in(1,2), c_{i s}>2 \underline{c}_{w}-\bar{c}_{w}$. A strong bidder's expected profit from colluding is now

$$
\pi_{i s}^{C}=\frac{1}{2}\left(\frac{\bar{c}_{w}}{2}-\frac{c_{i s}}{2}\right) \operatorname{Pr}\left(b\left(c_{i s}\right) \leq b\left(\tilde{c}_{j w}\right)\right)
$$

where $b\left(\tilde{c}_{j w}\right)$ denotes the minimum competing bid. First, note that $\operatorname{Pr}\left(b\left(c_{i s}\right)<b\left(c_{j s}\right)\right)<$ $\operatorname{Pr}\left(b\left(c_{i s}\right)<b\left(\tilde{c}_{j w}\right)\right)$. Second, $\frac{\bar{c}_{w}}{2}-\frac{c_{i s}}{2}>\bar{c}_{s}-c_{i s}$ if $c_{i s}>2 \bar{c}_{s}-\bar{c}_{w}$. Since $c_{i s}>2 \underline{c}_{w}-\bar{c}_{w}>2 \bar{c}_{s}-\bar{c}_{w}$, it follows that (A3) is higher than (A1) for any $c_{i s}>2 \underline{c}_{w}-\bar{c}_{w}$.

\section{B.2 Auction game with debarment}

\section{Proof of Proposition 2}

Trivially, in $t=T$ the strong bidders will collude for any private costs, as there is no future period where debarment can occur.

For $t<T$, two cases must be distinguished. When $t \leq T-\lambda$, a full $\lambda$-period debarment can be implemented. When $t>T-\lambda$, debarment will last less than $\lambda$ periods, as the number of remaining periods is lower than $\lambda$.

Case (i). In any period $t \leq T-\lambda$, a strong bidder $i$ with $c_{i s} \leq 2 \underline{c}_{w}-\bar{c}_{w}$ will collude if and only if

$$
\frac{1}{2}\left(\underline{c}_{w}-c_{i s t}\right) \tilde{q}-\frac{1}{2} \sum_{j=1}^{\lambda} \delta^{j} E\left(\pi_{t+j}\right) \geq \frac{1}{2}\left(\bar{c}_{s}-c_{i s t}\right) q
$$

where $\delta$ denotes the exponential discount factor and $E\left(\pi_{t+j}\right)$ the expected profit from playing the game in period $t+j \cdot{ }^{29}$ For ease of notation, $\tilde{q}$ denotes $\operatorname{Pr}\left(b\left(c_{i s t}\right) \leq b\left(\tilde{c}_{j w t}\right)\right)$ and $q$ denotes $\operatorname{Pr}\left(b\left(c_{i s t}\right) \leq b\left(c_{j s t}\right)\right)$.

Similarly, for $t>T-\lambda$, a strong bidder $i$ with $c_{i s} \leq 2 \underline{c}_{w}-\bar{c}_{w}$ will collude if and only if

$$
\frac{1}{2}\left(\underline{c}_{w}-c_{i s t}\right) \tilde{q}-\frac{1}{2} \sum_{j=1}^{T-t} \delta^{j} E\left(\pi_{t+j}\right) \geq \frac{1}{2}\left(\bar{c}_{s}-c_{i s t}\right) q
$$

Rearranging,

$$
\begin{cases}c_{i s t} \leq \frac{1}{\tilde{q}-q}\left(\underline{c}_{w} \tilde{q}-\bar{c}_{s} q-\sum_{j=1}^{\lambda} \delta^{j} E\left(\pi_{t+j}\right)\right), & \text { if } t \leq T-\lambda \\ c_{i s t} \leq \frac{1}{\tilde{q}-q}\left(\underline{c}_{w} \tilde{q}-\bar{c}_{s} q-\sum_{j=1}^{T-t} \delta^{j} E\left(\pi_{t+j}\right)\right), & \text { if } t>T-\lambda\end{cases}
$$

where $\tilde{q}>q$. In the benchmark case with no sanction, $\sum_{j=1}^{\lambda} \delta^{j} E\left(\pi_{t+j}\right)=0$. Under debarment, $\sum_{j=1}^{\lambda} \delta^{j} E\left(\pi_{t+j}\right)>0$. It follows that under debarment the private cost threshold below which the strong bidders will collude is lower than under no sanction.

29. $E\left(\pi_{t+j}\right)$ is a function of the costs bounds and of the expected private cost in the future. The expected private cost equals $\frac{\bar{c}_{s}+\underline{c}_{s}}{2}$, as costs are uniformly distributed. 
Case (ii) In any period $t \leq T-\lambda$, a strong bidder $i$ with $c_{i s t}>2 \underline{c}_{w}-\bar{c}_{w}$ will collude if and only if

$$
\frac{1}{2}\left(\frac{\bar{c}_{w}}{2}-\frac{c_{i s t}}{2}\right) \tilde{q}-\frac{1}{2} \sum_{j=1}^{\lambda} \delta^{j} E\left(\pi_{t+j}\right) \geq \frac{1}{2}\left(\bar{c}_{s}-c_{i s t}\right) q
$$

For $t>T-\lambda$, a strong bidder $i$ with $c_{i s t}>2 \underline{c}_{w}-\bar{c}_{w}$ will collude if and only if

$$
\frac{1}{2}\left(\frac{\bar{c}_{w}}{2}-\frac{c_{i s t}}{2}\right) \tilde{q}-\frac{1}{2} \sum_{j=1}^{T-t} \delta^{j} E\left(\pi_{t+j}\right) \geq \frac{1}{2}\left(\bar{c}_{s}-c_{i s t}\right) q
$$

Rearranging,

$$
\begin{cases}c_{i s t} \leq \frac{1}{\frac{q}{2}-q}\left(\frac{\bar{c}_{w}}{2} \tilde{q}-\bar{c}_{s} q-\sum_{j=1}^{\lambda} \delta^{j} E\left(\pi_{t+j}\right)\right), & \text { if } t \leq T-\lambda \\ c_{i s t} \leq \frac{1}{\frac{\tilde{q}}{2}-q}\left(\frac{\bar{c}_{w}}{2} \tilde{q}-\bar{c}_{s} q-\sum_{j=1}^{T-t} \delta^{j} E\left(\pi_{t+j}\right)\right), & \text { if } t>T-\lambda\end{cases}
$$

As for Case (i), under debarment the private cost threshold below which the strong bidders will collude is lower than under no sanction.

\section{Proof of Corollary 1}

As shown in the proof of Proposition 2, for any $t \leq T-\lambda$, a strong bidder $i$ will collude if and only if

$$
\begin{cases}c_{i s t} \leq \frac{1}{\tilde{q}-q}\left(\underline{c}_{w} \tilde{q}-\bar{c}_{s} q-\sum_{j=1}^{\lambda} \delta^{j} E\left(\pi_{t+j}\right)\right), & \text { if } c_{i s t} \leq 2 \underline{c}_{w}-\bar{c}_{w} \\ c_{i s t} \leq \frac{1}{\tilde{q}-q}\left(\frac{\bar{c}_{w}}{2} \tilde{q}-\bar{c}_{s} q-\sum_{j=1}^{\lambda} \delta^{j} E\left(\pi_{t+j}\right)\right), & \text { if } c_{i s t}>2 \underline{c}_{w}-\bar{c}_{w}\end{cases}
$$

It immediately follows that, as $\lambda$ increases, and thus $\sum_{j=1}^{\lambda} \delta^{j} E\left(\pi_{t+j}\right)$ increases, the private cost threshold below which the strong bidders will collude decreases.

\section{B.3 Auction game with fines}

\section{Proof of Proposition 3}

Trivially, in $t=T$ the strong bidders will collude for any private costs, as there is no future period where debarment can occur.

Case (i). In any period $t<T$, a strong bidder $i$ with $c_{i s t} \leq 2 \underline{c}_{w}-\bar{c}_{w}$ will collude if and only if

$$
\frac{1}{2}\left(\underline{c}_{w}-c_{i s t}\right) \tilde{q}-\frac{1}{2} \delta f \geq \frac{1}{2}\left(\bar{c}_{s}-c_{i s t}\right) q
$$

where $\delta$ denotes the exponential discount factor, $f>0$ denotes the fine and, for ease of notation, $\tilde{q}$ denotes $\operatorname{Pr}\left(b\left(c_{i s t}\right) \leq b\left(\tilde{c}_{j w t}\right)\right)$ and $q$ denotes $\operatorname{Pr}\left(b\left(c_{i s t}\right) \leq b\left(c_{j s t}\right)\right)$.

Rearranging,

$$
c_{i s t} \leq \frac{1}{\tilde{q}-q}\left(\underline{c}_{w} \tilde{q}-\bar{c}_{s} q-\delta f\right)
$$


where $\tilde{q}>q$. Since under no sanction $f=0$ and under a fine $f>0$, it immediately follows than under a fine the private cost threshold below which the strong bidders will collude is lower than under no sanction.

Case (ii). In any period $t<T$, a strong bidder $i$ with $c_{i s t}>2 \underline{c}_{w}-\bar{c}_{w}$ will collude if and only if

$$
\frac{1}{2}\left(\frac{\bar{c}_{w}}{2}-\frac{c_{i s t}}{2}\right) \tilde{q}-\frac{1}{2} \delta f \geq \frac{1}{2}\left(\bar{c}_{s}-c_{i s t}\right) q
$$

Rearranging,

$$
c_{i s t} \leq \frac{1}{\frac{\tilde{q}}{2}-q}\left(\frac{\bar{c}_{w}}{2} \tilde{q}-\bar{c}_{s} q-\delta f\right)
$$

\section{Additional analyses}

\section{C.1 Multilevel models}

In addition to our logistic and linear regressions, we also estimate multilevel logistic models (for collusion) and multilevel linear models (for bids) with the following basic specification:

$$
Y_{i g t}=\beta_{0}+\beta_{1} \text { DebarLong }+\beta_{2} \text { DebarShort }+\beta_{3} \text { Fine }+v_{i}+u_{i g}+\epsilon_{i g t},
$$

where $\beta_{0}$ denotes the constant, and DebarLong, DebarShort and Fine are treatment dummies taking value 1 if $i$ participated in the treatment, and 0 otherwise. The indicator $i$ denotes the second level of clustering, that accounts for 16 observations of each subject $i$ over time, with $v_{i}$ denoting the subject-specific random effect. The indicator $g$ denotes the third and highest level of clustering, that accounts for each subject nested in a group, with $u_{i g}$ denoting the group-specific random effect. $\epsilon_{i g t}$ is the error term.

Table 10 reports additional results on the effect of sanctions on collusion, estimating a threelevel mixed-effects logit regression.

Table 11 reports additional results on the effect of sanctions on strong bidders' bids, estimating a three-level mixed-effects linear regression.

Table 12 reports additional results on the effect of sanctions on winning bids, estimating a three-level mixed-effects linear regression.

\section{C.2 Efficiency}

Table 13 reports additional results on the effect of sanctions on efficiency, estimating a linear regression with standard errors clustered at the group level. 
Table 10: Impact of sanctions on collusion

\begin{tabular}{lccc}
\hline DV: Collusion & $(1)$ & $(2)$ & $(3)$ \\
\hline Baseline: No Sanction & & & \\
DebarLong & $-0.722^{* * *}$ & $-0.697^{* * *}$ & $-0.694^{* * *}$ \\
& $(0.062)$ & $(0.062)$ & $(0.061)$ \\
DebarShort & $-0.384^{* * *}$ & $-0.388^{* * *}$ & $-0.372^{* * *}$ \\
& $(0.080)$ & $(0.075)$ & $(0.071)$ \\
Fine & $-0.462^{* * *}$ & $-0.481^{* * *}$ & $-0.475^{* * *}$ \\
& $(0.079)$ & $(0.074)$ & $(0.069)$ \\
Cost & & & \\
Risk aversion & no & yes & yes \\
Demographics & no & yes & yes \\
\hline Wald test & no & no & yes \\
Pseudo $R^{2}$ & $11.99^{* * *}$ & $10.91^{* * *}$ & $12.94^{* * *}$ \\
$N$ & 0.818 & 0.823 & 0.827 \\
\hline
\end{tabular}

*** $p<0.01$; $^{* *} p<0.05$; $^{*} p<0.1$

Three-level mixed-effects logit regression. Standard errors in parentheses. All coefficients are reported as average marginal effects. Demographics denotes variables on age and gender.

Table 11: Impact of sanctions on strong bidders' bids

\begin{tabular}{lccc}
\hline DV: Bids & $(1)$ & $(2)$ & $(3)$ \\
\hline Baseline: No Sanction & & & \\
DebarLong & $-32.425^{* * *}$ & $-31.894^{* * *}$ & $-31.411^{* * *}$ \\
& $(5.502)$ & $(5.399)$ & $(5.209)$ \\
DebarShort & $-17.181^{* * *}$ & $-17.161^{* * *}$ & $-16.869^{* * *}$ \\
& $(5.531)$ & $(5.412)$ & $(5.215)$ \\
Fine & $-23.401^{* * *}$ & $-23.499^{* * *}$ & $-23.241^{* * *}$ \\
& $(5.495)$ & $(5.385)$ & $(5.188)$ \\
Cost & & $0.617^{* * *}$ & $0.617^{* * *}$ \\
& & $(0.034)$ & $(0.034)$ \\
Risk aversion & & -1.861 & -2.126 \\
& & $(1.504)$ & $(1.499)$ \\
Demographics & no & no & yes \\
\hline Wald test & $7.68^{* *}$ & $7.41^{* *}$ & $7.75^{* *}$ \\
$N$ & 1.406 & 1.406 & 1.406 \\
\hline
\end{tabular}

${ }^{* * *} p<0.01 ;{ }^{* *} p<0.05 ;{ }^{*} p<0.1$

Three-level mixed-effects linear regression. Standard errors in parentheses. Demographics denotes variables on age and gender. 
Table 12: Impact of sanctions on winning bids

\begin{tabular}{lccc}
\hline DV: Bids & $(1)$ & $(2)$ & $(3)$ \\
\hline Baseline: No Sanction & & & \\
DebarLong & $-26.981^{* * *}$ & $-25.145^{* * *}$ & $-25.679^{* * *}$ \\
& $(6.511)$ & $(5.839)$ & $(5.860)$ \\
DebarShort & -6.650 & $-9.833^{*}$ & $-9.793^{*}$ \\
& $(6.353)$ & $(5.665)$ & $(5.673)$ \\
Fine & $-21.610^{* * *}$ & $-20.031^{* * *}$ & $-20.373^{* * *}$ \\
& $(5.495)$ & $(5.788)$ & $(5.788)$ \\
Cost & & $0.397^{* * *}$ & $0.400^{* * *}$ \\
& & $(0.031)$ & $(0.031)$ \\
Risk aversion & & $-5.235^{*}$ & $-5.280^{*}$ \\
& & $(2.708)$ & $(2.702)$ \\
Demographics & no & no & yes \\
\hline Wald test & $10.82^{* * *}$ & $7.38^{* *}$ & $7.88^{* *}$ \\
$N$ & 768 & 768 & 768 \\
\hline
\end{tabular}

${ }^{* * *} p<0.01$; $^{* *} p<0.05$; $^{*} p<0.1$

Three-level mixed-effects linear regression. Standard errors in parentheses. Demographics denotes variables on age and gender.

Table 13: Impact of sanctions on efficiency

(1)

$(2)$

DV: Efficiency

\begin{tabular}{lcccccc}
\hline DebarShort & -0.154 & -0.153 & -0.156 & $-0.205^{* * *}$ & $-0.205^{* * *}$ & $-0.208^{* * *}$ \\
& $(0.098)$ & $(0.098)$ & $(0.097)$ & $(0.065)$ & $(0.065)$ & $(0.066)$ \\
DebarLong & & & & -0.051 & -0.051 & -0.052 \\
& & & & $(0.084)$ & $(0.082)$ & $(0.082)$ \\
Fine & 0.051 & 0.051 & 0.052 & & & \\
& $(0.084)$ & $(0.082)$ & $(0.082)$ & & & \\
No Sanction & 0.004 & 0.004 & 0.003 & -0.047 & -0.047 & -0.048 \\
& $(0.087)$ & $(0.084)$ & $(0.085)$ & $(0.047)$ & $(0.047)$ & $(0.047)$ \\
Cost & & $<0.001$ & $<0.001$ & & $<0.001$ & $<0.001$ \\
& & $(<0.001)$ & $(<0.001)$ & & $(<0.001)$ & $(<0.001)$ \\
Risk aversion & & 0.004 & 0.004 & & 0.004 & 0.004 \\
& & $(0.030)$ & $(0.030)$ & & $(0.030)$ & $(0.030)$ \\
Demographics & no & no & yes & no & no & yes \\
\hline Wald test & $9.83^{* * *}$ & $9.87^{* * *}$ & $10.10^{* * *}$ & $5.37^{*}$ & $5.44^{*}$ & $5.49^{*}$ \\
$R^{2}$ & 0.060 & 0.060 & 0.060 & 0.060 & 0.060 & 0.060 \\
$N$ & & 3.072 & & & 3.072 & \\
\hline
\end{tabular}

${ }^{* * *} p<0.01$; $^{* *} p<0.05{ }^{*} p<0.1$

Column 1: OLS. Standard errors in parentheses, clustered at the group level. DebarLong serves as the baseline category. Column 2: OLS. Standard errors in parentheses, clustered at the group level. Fine serves as the baseline category. Demographics denotes variables on age and gender. 


\section{C.3 Bidding dynamics}

Figure 5 shows that strong bidders' bids remain relatively stable over time.

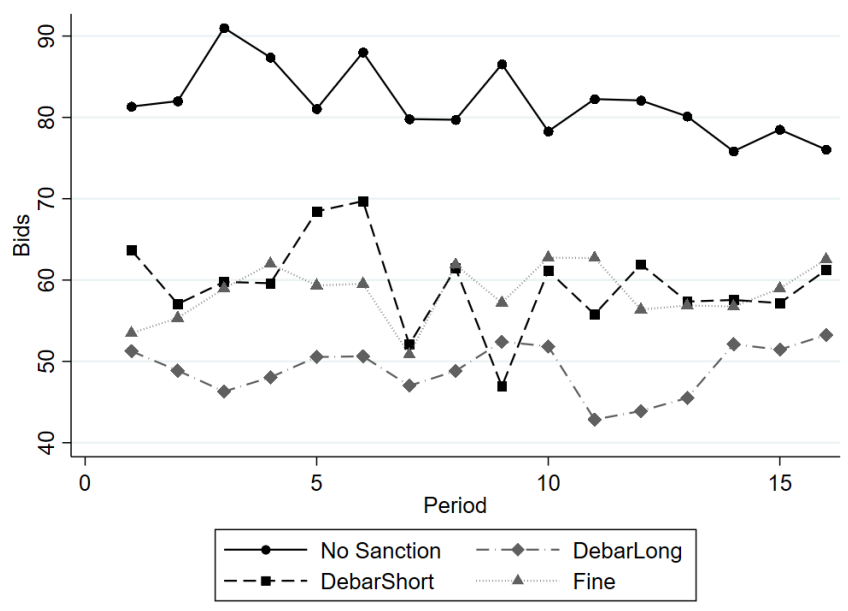

Figure 5: Strong bidders' bids over time.

\section{C.4 N-effects}

Subjects stated they would run faster in a $5 \mathrm{~K}$ run with 50 competitors $(m=5.193, s d=2.003$ ) than in a $5 \mathrm{~K}$ run with 500 competitors $(m=4.474, s d=2.194)$, the difference being statistically significant (paired t-test, $p<0.001$ ). This difference was consistent across all treatments for 50 competitors (No Sanction: $m=5.229$, $s d=2.004$; DebarLong: $m=5.104$, $s d=1.930$; DebarShort: $m=5.438, s d=2.042$; Fine: $m=5.000, s d=2.012$ ) and 500 competitors (No Sanction: $m=4.646, s d=2.279$; DebarLong: $m=4.604$, $s d=2.207$; DebarShort: $m=4.396, s d=2.254$; Fine: $m=4.250, s d=2.007$ )

Competitive feelings decreased as the number of competitors increased from $10(\mathrm{~m}=$ $4.266, s d=1.873)$, to $30(m=3.828, s d=1.554)$, to $50(m=3.422, s d=1.509)$, to 100 ( $m=3.188, s d=1.816$ ), the difference between all scenarios being statistically significant (paired t-test, $p<0.001$ ). This difference was consistent across all treatments for 10 (No Sanction: $m=4.250, s d=1.751$; DebarLong: $m=4.167$, $s d=1.952$; DebarShort: $m=4.583$, $s d=$ 1.968; Fine: $m=4.063$, $s d=1.774$ ), for 30 (No Sanction: $m=3.980$, sd $=1.451$; DebarLong: $m=3.583, s d=1.567$; DebarShort: $m=4.000, s d=1.660$; Fine: $m=3.750, s d=1.494$ ), 50 (No Sanction: $m=3.625, s d=1.482$; DebarLong: $m=3.021$, $s d=1.362$; DebarShort: $m=3.479, s d=1.634$; Fine: $m=3.563, s d=1.472$ ) and 100 competitors (No Sanction: $m=3.500, s d=1.815$; DebarLong: $m=2.854, s d=1.672$; DebarShort: $m=2.917, s d=1.756$; Fine: $m=3.479, s d=1.916)$. 


\section{C.5 Power analysis}

This subsection presents the results of an ex ante power analysis for the tests used to estimate our hypothesized treatment effects. The logic of ex ante power analysis and the rules of thumb that can be used to improve the efficiency of experimental designs (see List, Sadoff, and Wagner 2011) also guided us in the design phase and in the adjustment of our sample size. Our measure of effect size is Cohen's $d$, i.e. the difference between the means of two treatment groups divided by their standard deviation:

$$
d=\frac{m_{1}-m_{2}}{s}
$$

Hypothesis 1 (Collusion): Using a one-tailed t-test for 12 independent observations per treatment, and assuming (i) a 5\% significance level, (ii) an expected difference of 60 percentage points (0.60) between No Sanction and DebarLong, (iii) a difference of 30 percentage points (0.30) between both No Sanction and DebarShort and No Sanction and Fine, and (iv) a standard deviation of 0.30 in all treatments, the ex ante power of the statistical test is $99.90 \%$ for the No Sanction-DebarLong comparison, and $76.68 \%$ for the other two comparisons.

Hypothesis 2 (Collusion): Using a one-tailed t-test for 12 independent observations per treatment, and assuming (i) a 5\% significance level, (ii) an expected difference of 30 percentage points (0.30) between DebarLong and DebarShort, and (iii) a standard deviation of 0.30 in these treatments, the ex ante power of the statistical test is $76.68 \%$.

Hypothesis 1 (Bids): Using a one-tailed t-test for 12 independent observations per treatment, and assuming (i) a 5\% significance level, (ii) an expected difference of 40 points between No Sanction and DebarLong, (iii) a difference of 20 points between both No Sanction and DebarShort and No Sanction and Fine, and (iv) a standard deviation of 20.00 in all treatments, the ex ante power of the statistical test is $99.90 \%$ for the No Sanction-DebarLong comparison, and $76.68 \%$ for the other two comparisons.

\section{Instructions}

\section{INSTRUCTIONS}

Welcome to this experiment in decision making. Please read the following instructions carefully. You can earn money in this experiment. Your earnings depend on both your decisions and on the decisions of the other participants. At the end of the experiment, the total amount of money earned will be paid to you in cash. In addition, you will receive a fee of 6 Euros for participating in the experiment.

Throughout the experiment, monetary amounts are not quoted in Euro, but in Points. Your total earnings will thus be initially calculated in Points. At the end, the total amount of money earned during the experiment will be converted into Euro, where: 1 Point $=0.10$ Euro. 
The experiment consists of three parts. It is important that you understand the instructions of each part before you start the experiment. These are the instructions for Part 1 . Instructions for Part 2 will be handed out when Part 1 is completed. Instructions for Part 3 will be handed out when Part 2 is completed. Part 1 and Part 2 consist of a sequence of 8 rounds respectively, Part 3 consists of a sequence of 16 rounds.

At the end of the experiment, you will receive EITHER your earnings in Part 1 ( 8 rounds) plus your earnings in Part 2 (8 rounds) OR your earnings in Part 3 (16 rounds). Whether you receive your earnings in Part 1 plus your earnings in Part 2 OR your earnings in Part 3, will be determined randomly at the end of the experiment. Note that your earnings may be negative in some rounds. However, your accumulated earnings in any Part will never become negative. It is important that you pay the same attention to each part, because each part may be paid out.

Each participant is a bidder in an auction. You will be part of a group of four bidders: you and three other participants. There are two types of bidders: A-bidders and B-bidders. There are two A-bidders and two Bbidders in each group.

All participants receive the same instructions and all decisions are made anonymously. Talking or communicating with other participants is not permitted throughout the entire experiment. Please do not use your cell phones or electronic devices during the experiment. Failure to comply implies exclusion from the experiment and loss of all earnings. If you have any questions or need assistance, please raise your hand. An experimenter will then help you at your desk.

\section{PART 1}

Part 1 consists of a sequence of 8 rounds. In each round, you and the three other members of your group participate in an auction. At the beginning of each round, you are assigned the role of either an A-bidder type or a B-bidder type randomly. The composition of your group remains the same throughout the 8 rounds of Part 1 .

The outcome of each round is independent from the outcome of previous rounds. This means that your earnings in any given round are not affected by your or other group members' decisions in previous rounds.

In each round, a project is auctioned off. You can submit a bid to obtain the project. The project is awarded to the bidder who submits the lowest bid. If you obtain the project (= win the auction), you earn the amount you bid minus your cost of implementing the project. Your cost will be randomly assigned to you at the beginning of each round. If you do not obtain the project, you earn 0 Points.

Think of this as a situation where you act as an entrepreneur. The auctioneer (for example, the government or a company) is willing to pay an amount of money to an entrepreneur to implement the project. The auctioneer will award the project to the entrepreneur asking for the lowest amount of money. This entrepreneur will receive the amount of money she asked for in the auction (= the bid) minus the cost of implementing the project. The other entrepreneurs who asked for higher amounts will not be awarded the project, and therefore neither receive nor pay anything.

Step 1 At the beginning of each round, you are assigned a random cost. The cost of A-bidders lies between 20 and 60 Points. The cost of B-bidders lies between 80 and 120 Points. 
All costs are integer numbers. Each cost has the same probability of being picked. That is, if you are an A-bidder, any cost between 20 and 60 will be assigned to you with the same probability. Likewise, if you are a B-bidder, any cost between 80 and 120 will be assigned to you with the same probability. The cost assigned to one participant does not depend on the costs of the other participants. Therefore, your cost is probably different from that of the other bidders.

You will be informed about your own cost at the beginning of each round. This value will not be revealed to the other bidders. This also means that you will not be informed about the other bidders' costs.

Step 2 The auction takes place. Each bidder makes one decision: You decide, how much you would like to bid for the project. You can submit any bid in integer numbers between 0 and 140 Points.

All bidders submit their bids at the same time. You will not see the bids submitted by the other bidders before each bidder has submitted her bid. The winner of the auction is the bidder submitting the lowest bid. This bidder thus obtains the project. If two or more bidders submit an equal bid and this bid is the lowest, the winner is chosen randomly among these bidders.

If you win the auction, you receive:

$$
\text { earnings }=\text { bid }- \text { cost. }
$$

If you do not win the auction, you receive:

earnings $=0$.

Example: Your cost is 20 and you bid 30. If 30 is the lowest bid, you win the auction and receive $10(=30-20)$. If 30 is not the lowest bid (for example, another bidder submits a bid of 25), you do not win the auction and receive 0 .

Note that you can also incur a loss. This will happen if you submit a bid below your cost and you win the auction with this bid. The amount lost will be subtracted from the earnings you made up to that round. Your final earnings will never be negative, however.

Example: Your cost is 30 and you bid 10. If 10 is the lowest bid, you win the auction. However, your bid being lower than your cost, you earn $-20(=10-30)$.

Step 3 The outcome of the auction is communicated to each bidder. You will learn whether you won the auction, which bids were submitted by the other bidders and your earnings in that round.

Step 4 Then a new round will begin. In the new round, you will again bid for an identical project. When a new round begins, each bidder is assigned a new bidder type (A or B) and a new cost. Your bidder type and your cost in one round do not depend on your bidder type and your cost in any other round. 


\section{PART 2}

Part 2 consists of a sequence of 8 rounds. In each round, you and the other three members of your group participate in an auction, but the rules are different from those in Part 1. At the beginning of each round, you are assigned the role of either an A-bidder type or a B-bidder type randomly. You will be in the same group as in Part 1. You are part of the same group as in Part 1. The composition of your group remains the same throughout the 8 rounds of Part 2.

The outcome of each round is independent from the outcome of previous rounds. This means that your earnings in any given round are not affected by your or others' decisions in previous rounds.

Step 1 At the beginning of each round, you are assigned a random cost. As in Part 1, the cost of A-bidders lies between 20 and 60 Points, and the cost of B-bidders lies between 80 and 120 Points. You will be informed about your own cost at the beginning of each round. The same procedure as in Part 1 applies.

Step 2 Each A-bidder can decide to form an agreement with the other A-bidder. Only A-bidders are offered the option to form an agreement with each other. If you are assigned the role of an A-bidder, the following question appears on your screen: 'Would you like to form an agreement with the other A-bidder in your group?' Each A-bidder can choose Yes or No. An agreement forms if both A-bidders choose Yes. In other words, no agreement is made unless both A-bidders want to make one.

If an agreement forms: If an agreement forms, only one A-bidder can participate in the auction. This A-bidder is called the designated bidder. The A-bidder who does not participate in the auction is called the non-designated bidder.

The designated bidder will be determined as follows: each A-bidder states an amount that she is willing to transfer to the other A-bidder in case she becomes the designated bidder. This amount of money will compensate the non-designated bidder for not participating in the auction (= transfer). The A-bidder stating the higher amount becomes the designated bidder and participates in the auction. The A-bidder stating the lower amount becomes the non-designated bidder. An A-bidder can state any amount between 0 and 120 Points. In case both A-bidders state the same amount, the designated bidder will be determined randomly.

Example: Both A-bidders choose Yes and an agreement forms. You are an A-bidder and state 40 Points, while the other A-bidder states 20 Points. This means: You are the designated bidder. The other A-bidder is the nondesignated bidder. An amount of 40 Points is automatically transferred from you to the non-designated bidder. You participate in the auction, the non-designated bidder does not.

Once both A-bidders have stated the amount they are willing to transfer to the other A-bidder in order to become the designated bidder, they will be informed about the amounts they stated, the amount of the transfer and whether they will participate in the auction (= designated bidder) or not (= non-designated bidder). B-bidders will not know whether an agreement has been formed. Then the designated bidder and the B-bidders will proceed to the auction. The designated bidder will submit two bids: one bid for herself and another bid on behalf of the non-designated bidder.

If no agreement forms: If no agreement forms, both A-bidders will learn about it and proceed to the auction with 
the B-bidders. B-bidders will not know whether an agreement has been formed.

Step 3 The auction takes place.

If an agreement has been formed: If an agreement has been formed, the designated bidder and the B-bidders submit their bids in the auction. In addition to his own bid, the designated bidder submits a bid on behalf of the non-designated bidder. The designated bidder can submit any bid on behalf of the non-designated bidder, as long as this bid is higher than her own bid and below or equal to 140 Points. The earnings of the designated bidder in this round will depend on the transfer made to the non-designated bidder and on whether she wins the auction.

If the designated bidder wins the auction, she receives:

$$
\text { earnings }=\text { bid }- \text { cost }- \text { transfer. }
$$

The non-designated bidder receives:

$$
\text { earnings }=\text { transfer }
$$

The B-bidders receive:

$$
\text { earnings }=0 \text {. }
$$

If the designated bidder does not win the auction, she receives:

$$
\text { earnings }=0 \text { - payment. }
$$

The non-designated bidder receives:

$$
\text { earnings }=\text { transfer }
$$

The B-bidder who wins the auction receives:

$$
\text { earnings }=\text { bid }- \text { cost. }
$$

The other B-bidder receives:

$$
\text { earnings }=0 \text {. }
$$

If no agreement has been formed: If no agreement has been formed, all bidders submit their bids. The general rules apply: the winning bidder receives her bid minus her cost. The other bidders receive 0 Points. 
Step 4 The outcome of the auction is communicated to each bidder. You will learn whether you won the auction, which bids were submitted by the other bidders and your earnings in that round.

Step 5 Then a new round will begin. In the new round, you will again bid for an identical project. When a new round begins, each bidder is assigned a new bidder type (A or B) and a new cost. Your bidder type and your cost in one round do not depend on your bidder type and your cost in any other round.

PART 3 [No sanction] Part 3 consists of a sequence of 16 rounds. In each of these rounds, you participate in an auction. At the beginning of Part 3, you are assigned the role of either an A-bidder type or a B-bidder type randomly. You will keep your bidder type during these 16 rounds. You will not be in the same group as in Part 1 and Part 2. You are now part of a new group, together with 3 participants with whom you have not interacted before. The composition of your group remains the same throughout the 16 rounds.

Apart from that, each round proceeds according rules that are similar to those in Part 2. Differences exist in Step 5 .

Step 1 At the beginning of each round, you are assigned a random cost. As in Part 1 and Part 2, the cost of A-bidders lies between 20 and 60 Points. The cost of B-bidders lies between 80 and 120 Points. You will be informed about your own cost at the beginning of each round.

Step 2 A-bidders decide whether to form an agreement.

Step 3 The auction takes place.

Step 4 The outcome of the auction is communicated to each bidder. You will learn whether you won the auction, which bids were submitted by the other bidders and your earnings in that round.

Step 5 At the end of each round, you are asked to guess the other bidders' costs. On your screen, you will be informed about the other bidders' bids. You will then be asked: 'What do you think: What are the costs of these bidders?' You will state a guess for each of the three other bidders. For each guess, you will receive 2 Points if the distance between your guess and the actual cost is smaller than or equal to 5 Points. If the distance between your guess and the actual cost is larger than 5 Points, you will receive 0 Points.

Then a new round will begin. In the new round, you will again bid for an identical project. When a new round begins, each bidder is assigned a new cost. Your cost in one round will not depend on your cost in any other round. Remember that you will keep your bidder type throughout all 16 rounds.

PART 3 [DebarLong] Part 3 consists of a sequence of 16 rounds. In each of these rounds, you participate in an auction. At the beginning of Part 3, you are assigned the role of either an A-bidder type or a B-bidder type 
randomly. You will keep your bidder type during these 16 rounds. You will not be in the same group as in Part 1 and Part 2. You are now part of a new group, together with 3 participants with whom you have not interacted before. The composition of your group remains the same throughout the 16 rounds.

Apart from that, each round proceeds according rules that are similar to those in Part 2. Differences exist in Step 4 and Step 6.

Step 1 At the beginning of each round, you are assigned a random cost. As in Part 1 and Part 2, the cost of A-bidders lies between 20 and 60 Points. The cost of B-bidders lies between 80 and 120 Points. You will be informed about your own cost at the beginning of each round.

Step 2 A-bidders decide whether to form an agreement.

Step 3 The auction takes place.

Step 4 If an agreement forms, both A-bidders can be excluded from the game for a duration of six rounds. If the A-bidders are excluded, they will not participate in the auction for the following six rounds. Only the Bbidders will participate in the auction in these six rounds. If the A-bidders are excluded in round 10 or later, they will be excluded for the remaining rounds of Part 3. The A-bidders can only be excluded simultaneously.

The probability of exclusion is $50 \%$. Note that the A-bidders can only be excluded if an agreement forms. If no agreement forms, the A-bidders cannot be excluded.

Note that you will run the risk of exclusion only for an agreement made in the current round. This means that you will not be excluded in a round if no agreement forms in that round. If you formed an agreement in a previous round, you will not be excluded for this agreement in following rounds.

Both the A-bidders and the B-bidders will know whether the A-bidders have been excluded. When submitting their bids, B-bidders will always know whether the A-bidders are excluded from the auction.

Step 5 The outcome of the auction is communicated to each bidder. You will learn whether you won the auction, which bids were submitted by the other bidders and your earnings in that round.

Step 6 At the end of each round, you are asked to guess the costs of bidders who participated in the auction. On your screen, you will be informed about the bids of these bidders. You will then be asked: 'What do you think: What are the costs of these bidders?'. You will state a guess for each bidder who participated in the auction. For each guess, you will receive 2 Points if the distance between your guess and the actual cost is smaller than or equal to 5 Points. If the distance between your guess and the actual cost is larger than 5 Points, you will receive 0 Points. 
Then a new round will begin. In the new round, you will again bid for an identical project. When a new round begins, each bidder is assigned a new cost. Your cost in one round will not depend on your cost in any other round. Remember that you will keep your bidder type throughout all 16 rounds.

\section{PART 3 [DebarShort]}

\section{Step 1-3 As in DebarLong.}

Step 4 If an agreement forms, both A-bidders can be excluded from the game for a duration of three rounds. If the A-bidders are excluded, they will not participate in the auction for the following three rounds. Only the B-bidders will participate in the auction in these three rounds. If the A-bidders are excluded in round 13 or later, they will be excluded for the remaining rounds of Part 3. The A-bidders can only be excluded simultaneously.

The probability of exclusion is $50 \%$. Note that the A-bidders can only be excluded if an agreement forms. If no agreement forms, the A-bidders cannot be excluded.

Note that you will run the risk of exclusion only for an agreement made in the current round. This means that you will not be excluded in a round if no agreement forms in that round. If you formed an agreement in a previous round, you will not be excluded for this agreement in following rounds.

Both the A-bidders and the B-bidders will know whether the A-bidders have been excluded. When submitting their bids, B-bidders will always know whether the A-bidders are excluded from the auction.

Step 5-6 As in DebarLong.

PART 3 [Fine] Part 3 consists of a sequence of 16 rounds. In each of these rounds, you participate in an auction. At the beginning of Part 3, you are assigned the role of either an A-bidder type or a B-bidder type randomly. You will keep your bidder type during these 16 rounds. You will not be in the same group as in Part 1 and Part 2. You are now part of a new group, together with 3 participants with whom you have not interacted before. The composition of your group remains the same throughout the 16 rounds.

Apart from that, each round proceeds according rules that are similar to those in Part 2. Differences exist in Step 4 and Step 6.

Step 1 At the beginning of each round, you are assigned a random cost. As in Part 1 and Part 2, the cost of A-bidders lies between 20 and 60 Points. The cost of B-bidders lies between 80 and 120 Points. You will be informed about your own cost at the beginning of each round.

Step 2 A-bidders decide whether to form an agreement. 
Step 3 The auction takes place.

Step 4 If an agreement forms, both A-bidders might have to pay a fine of 24 Points. If a fine is imposed, an amount of 24 Points is deducted from the earnings that each A-bidder has made up to that round.

The probability of a fine is $50 \%$. Note that a fine can only be imposed if an agreement forms. If no agreement forms, the A-bidders are not fined.

Note that you will run the risk of paying a fine only for an agreement made in the current round. This means that you will not have to pay a fine in a round if no agreement forms in that round. If you formed an agreement in a previous round, you will not be fined for this agreement in following rounds.

B-bidders will not know whether the A-bidders have been fined.

Step 5 The outcome of the auction is communicated to each bidder. You will learn whether you won the auction, which bids were submitted by the other bidders and your earnings in that round.

Step 6 At the end of each round, you are asked to guess the other bidders' costs. On your screen, you will be informed about the other bidders' bids. You will then be asked: What do you think: What are the costs of these bidders? You will state a guess for each of the three other bidders. For each guess, you will receive 2 Points if the distance between your guess and the actual cost is smaller than or equal to 5 Points. If the distance between your guess and the actual cost is larger than 5 Points, you will receive 0 Points.

Then a new round will begin. In the new round, you will again bid for an identical project. When a new round begins, each bidder is assigned a new cost. Your cost in one round will not depend on your cost in any other round. Remember that you will keep your bidder type throughout all 16 rounds.

\section{Control Questions}

Control questions Part 1

1) Is the following statement correct? In each round of Part 1 , you will be matched with different participants. [No]

2) Is the following statement correct? In each round of Part 1, you will be assigned a new role and a new cost. [Yes]

3) Suppose you win the auction. Your cost is 20 and your bid is 40 . How much do you earn? [20]

4) Suppose you win the auction. Your cost is 60 and your bid is 30. How much do you earn? [-30]

5) Suppose your cost is 90. Are you an A-bidder or a B-bidder? [B-bidder] 
1) Suppose one A-bidder clicks Yes and the other A-bidder clicks No when deciding whether to make an agreement. Is an agreement formed? [No]

2) Suppose you are an A-bidder. An agreement forms. You propose a transfer of 40, the other A-bidder proposes a transfer of 50. Do you submit a bid in the auction? [No]

3) Suppose you are an A-bidder and your cost is 20. An agreement forms and you become the designated bidder. Suppose you transfer 30 to the non-designated bidder, then bid 80 in the auction and win the auction. How much do you earn? [30 (=80-20-30)]

4) Suppose you are an A-bidder and your cost is 20. An agreement does not form. The other A-bidder bids 40. You bid 30 and win the auction. How much do you earn? [10 (=30-20)]

5) Suppose you are an A-bidder and your cost is 60 . An agreement forms. You bid 80 in the auction. How much money can you transfer at most to the non-designated bidder without making a loss? [20]

Control questions Part 3 [No sanction]

1) Is the following statement correct? In Part 3, you will be matched with other participants than in Part 1 and Part 2. [Yes]

2) Is the following statement correct? In each round, you will be assigned a new role. [No]

3) Is the following statement correct? In each round, you will be assigned a new cost. [Yes]

Control questions Part 3 [Debarment]

1) Is the following statement correct? In Part 3, you will be matched with other participants than in Part 1 and Part 2. [Yes]

2) Is the following statement correct? In each round, you will be assigned a new role. [No]

3) Is the following statement correct? In each round, you will be assigned a new cost. [Yes]

4) Suppose the A-bidders have been excluded in round 2. How many bidders will submit a bid in the auction in rounds 3,4 and 5 ? [2]

5) Suppose an agreement between the A-bidders does not form. Can they be excluded? [No]

6) Can the B-bidders be excluded? [No]

Control questions Part 3 [Fine]

1) Is the following statement correct? In Part 3, you will be matched with other participants than in Part 1 and Part 2. [Yes]

2) Is the following statement correct? In each round, you will be assigned a new role. [No]

3) Is the following statement correct? In each round, you will be assigned a new cost. [Yes]

4) Suppose an agreement between the A-bidders does not form. Can they be fined? [No]

5) Can the B-bidders be fined? [No] 